\title{
Financing Strategy and Carbon Emission Abatement in a Supply Chain considering Retailers' Competition
}

\author{
Man Yu ${ }^{1}{ }^{1}$ Tuo Li $\mathbb{D}^{1},{ }^{2}$ and Zhanwen Shi $\mathbb{D}^{3}$ \\ ${ }^{1}$ School of Economics and Trade, Hunan University, Changsha 410006, China \\ ${ }^{2}$ National Bureau of Statistics, Beijing 100826, China \\ ${ }^{3}$ School of Business Administration, Zhongnan University of Economics and Law, Wuhan 430073, China \\ Correspondence should be addressed to Zhanwen Shi; szw@zuel.edu.cn
}

Received 19 June 2021; Revised 23 August 2021; Accepted 24 September 2021; Published 8 October 2021

Academic Editor: Akbar Ali

Copyright ( $) 2021$ Man Yu et al. This is an open access article distributed under the Creative Commons Attribution License, which permits unrestricted use, distribution, and reproduction in any medium, provided the original work is properly cited.

\begin{abstract}
This paper investigates the issues of financing channels (bank credit financing, trade credit financing, and dual-channel financing) and carbon emission abatement in a supply chain consisting of one capital-constrained manufacturer and two capital-constrained retailers. Compared with bank credit, we find that every member can make more profit under trade credit when only one financing channel is available. When both bank credit and trade credit are available, the retailers' financing strategy highly depends on the interest rates charged by the creditors. In addition, we also examine the impact of financing channels on emission abatement. It shows that the manufacturer reduces more carbon emissions under trade credit. Interestingly, the emission abatement has nothing to do with trade credit interest rate when retailers only adopt trade credit, whereas it is closely related to trade credit interest rate under dual-channel financing.
\end{abstract}

\section{Introduction}

Recently, global natural disasters and extreme weather occur frequently. The frequency of floods, high temperature, drought, freezing, typhoons, and other disasters has increased significantly. One of the main causes of these environmental crises is global warming, which is trigged by greenhouse emissions, such as carbon dioxide emissions. Since the Kyoto Protocol came into effect in 2005, governments that signed the agreement have taken various measures to reduce carbon emissions. However, the carbon emissions around the world have not decreased considerably [1]. To curb carbon emissions effectively, nearly 200 countries signed the Paris Agreement and committed to realize climate goals in 2030 [2]. As the main contributor of carbon emissions, firms need to make efforts to reduce carbon emissions in the manufacturing process. On the other hand, consumers pay more attention to environmental protection nowadays [3], which also pushes firms to reduce carbon emissions.

Capital constraint is a very common problem faced by many firms [4]. To solve this problem, the capital- constrained enterprises may borrow from a supply chain partner by trade credit or a commercial bank by trade credit [5]. For the start-up and small-and medium-sized enterprises, it may be easier to access trade credit due to lack of credit information and limited liability structure $[6,7]$. Some firms may avail a loan from a bank or from their upstream firms. Then, an interesting issue that arises from the above phenomenon is what financing method a capital-constrained firm should choose when both financing channels are available. What if adopting two financing ways? How does financing channel affect carbon emission abatement? Yet, little attention has been paid to the above issues.

To fill the aforementioned gap, we establish a green supply chain consisting of one capital-constrained manufacturer and two capital-constrained retailers. The manufacturer has to invest in carbon emission reduction due to consumer's environmental awareness and environmental policies. The manufacturer borrows from a bank when necessary. The retailers borrow either from the manufacturer by trade credit or from a bank by bank credit, or both channels at the same time. By comparing each member's optimal decision under different financing methods, we find 
that the retailers place larger orders under trade credit. The reason behind this result is that the manufacturer offers a lower wholesale place in this scenario. The result also shows that the capital-constrained firms can make more profits under trade credit than that under bank credit when only one financing method is available. On the other hand, the manufacturer reduces more carbon emissions under trade credit. Interestingly, under trade credit, the retailers' optimal order quantities are not affected by the interest rate and the emission abatement is immune to trade credit interest. We also investigate the conditions under which each financing method is adopted when both financing methods are available. The findings show that, when the trade credit interest is lower than bank interest rate, the retailers borrow more money from the manufacturer instead of crediting only from the manufacturer. Only when the trade credit interest is much lower than bank credit interest, the retailers will borrow all needed funds from the manufacturer. In addition, we further discuss the impact of dual-channel financing on carbon emission reduction and find that carbon emission reduction is closely related to trade credit interest and bank credit interest charged on the manufacturer and retailers. It shows that when trade credit interest is twice higher than the bank credit interest on the manufacturer, the carbon emission reduction level increases in bank interest rate on retailers. When the bank interest rate on the manufacturer is relatively larger, the carbon emission reduction level increases in trade credit interest.

The remainder of this paper is organized as follows. Section 2 reviews the relevant literature. Section 3 describes the basic modeling framework. Section 4 analyzes each member's optimal decision in different financing cases. Section 5 does some numerical experiments to investigate how various parameters affect the participators' optimal decisions. Section 6 presents the insights and conclusions of this study.

\section{Literature Review}

This research is relevant to carbon emission abatement. Firms abate carbon emissions due to governmental regulations in some countries and areas. Krass et al. [8] show that firms have to adopt green emission reduction technology since governments charge environmental taxes on carbon emissions. Drake et al. [9] investigate as to how emission tax influences an enterprise's technology choice and capacity decision by constructing a two-stage model. Xu et al. [10] investigate the effectiveness of different low carbon policies on reducing carbon emissions. Lee [11] considers a supply chain consisting of two manufacturers, one of whom produces green products and another who produces nongreen products, and shows that the competition brings more profit for them. Considering the impact of GHG emissions, Marchi et al. [12] compare the order quantity and production rate decisions in different scenarios. Hong and Guo [13] study the optimal retail price decision in a supply chain in which the supplier decides the product greenness. Cohen et al. [3] investigate how demand uncertainty affects each participator when the government provides subsidy to end consumers to stimulate adopting green technology. Under carbon cap-and-trade regulation, Choi [14] establish a newsvendor model to investigate the emission abatement issue in a supply chain where the decision-maker is lossaverse.

The carbon emission abatement is also driven by consumers' eco-friendly awareness. Du et al. [15] discuss the decision of the optimal greening level of each firm when it makes decisions separately. Yang and Chen [16] study how supply chain contracts affect a manufacturer's carbon emission reduction when considering consumers' environmental awareness. Swami and Shah [17] examine whether a two-part tariff contract can coordinate the supply chain when considering firms investing in carbon emission reduction. Xu et al. [10] suggest that a cost-sharing contract is able to achieve supply chain coordination. Dong et al. [18] examine firms' optimal decisions considering carbon emission abatement investment and suggest that a revenue sharing contract can coordinate a sustainable supply chain. Tong et al. [19] suggest that, when consumers pay attention to technologies of reducing carbon emissions, more firms are willing to invest in $\mathrm{R} \& \mathrm{D}$.

Some literature also suggests that firms may actively make a costly effort to reduce carbon emission to make more profit or to take social responsibility. Ghosh and Shah [20] analyze how channel structures impact the green levels, price, and profits of supply chain members. Shi et al. [21] examine the investment strategy in green product and find that a supplier makes more profit when both retailers invest in green technology. Zhu and $\mathrm{He}$ [22] discuss how green product design was affected by supply chain structures in competing supply chains. Luo et al. [23] investigate how the emission abatement affects the performance of a supply chain comprising two competitive manufacturers in competition and cooperation scenarios, respectively. Wang and Sun [24] suggest that a manufacturer is willing to invest in green products when the sales volume is high in the direct channel.

Our work also considers consumers' environmental awareness, whereas our work differs from the literature above in at least two dimensions. First, we consider a supply chain consisting of capital-constrained retailers, who may finance by bank credit or by trade credit. Under some conditions, the manufacturer may also borrow from a bank. Second, this paper investigates the impacts of different financing methods on carbon emission reduction, and finds that carbon emission reduction is immune to trade credit.

This work is also closely related to enterprise financing. According to funding sources, financing can be divided into external financing, such as bank credit financing, and internal financing, such as trade credit financing.

In recent years, researchers have paid considerable attention to trade credit and investigated the roles of trade credit. Tiwari et al. [25] establish an EOQ model to analyze the optimal decisions about deteriorating products. Otrodi et al. [26] discuss the optimal pricing and ordering decisions in a supply chain where the supplier offers trade credit to the retailer and the retailer provides trade credit to customers. Marchi et al. [27] study how trade credit that is offered from a buyer to a vendor affects a vendor's production capability 
and the performance of a supply chain. When retailers compete in terminal market, Wu et al. [28] show that a manufacturer can use trade credit to respond to a dominant retailer's bargaining and the weak retailer can benefit from trade credit. Li et al. [29] establish a multi-period model to analyze the relationship between a supplier's trade credit term strategy and a retailer's optimal order quantity decision by using game theory. Zou and Tian [30] examine the retailer's optimal payment strategy and ordering decision when two-part trade credit is available. Chod [6] suggest that when a retailer orders multiple products from different suppliers, trade credit can mitigate the inventory distortion. Yang and Birge [31] suggest that trade credit improves supply chain performance because a creditor can share the distress risk with a borrower. Ren et al. [32] study how trade credit affects each member's pricing decision and profit in a supply chain. Yan et al. [33] examine how each party makes a decision in a supply chain with capital-constrained retailer and suggest that a partial credit guarantee is able to achieve channel coordination considering bank credit financing.

This work is also related bank to credit financing. Ries et al. [34] study how financial conditions affect a retailer's optimal order quantity and the payment decision. Boyabatli and Toktay [35] inspect a case in which a manufacturer lacks capital and borrows from a bank aiming to maximize its profit. Yang et al. [36] show the impact of bank financing on each member's optimal decision by establishing a supply chain comprising a supplier and two competitive retailers who borrow money from a bank. Kouvelis and Zhao [37] study the supply chain coordination considering retailer's bankruptcy cost. Researchers also pay attention to compare trade credit with bank credit and investigate the preferences of the financing channel. For example, Bing et al. [38] inspect the financing equilibriums when a capital-constrained retailer uses bank credit financing and trade credit financing, respectively. Kouvelis and Zhao [39] also examine the impact of interest rate on firms' financing choices. Deng et al. [40] provide the equilibriums under buyer finance and bank finance, respectively, and show that a buyer may offer suppliers finance even if its capital opportunity cost is higher than bank interest rate. Tang et al. [41] compare purchase ordering financing and bank credit financing and suggest that purchase ordering financing is efficient in lowering performance risk.

This paper complements the abovementioned literature by investigating different financing channels considering consumers' environmental awareness. Different from the above studies, first, we consider the case in which two capitalconstrained retailers compete for items in the market. Second, we not only analyze the scenarios in which either trade credit or bank credit is adopted but also examine the scenario in which both trade credit and bank credit are availed under a competing situation. Third, this paper also inspects the impact of financing methods on carbon emission abatement.

\section{Model Description}

We consider a supply chain consisting of one manufacturer (called "she") and two capital-constrained retailers (called "he"). The manufacturer and the retailers are engaged in a
Stackelberg game in which the manufacturer is the leader. The retailers compete for sales quantities in the market. The capital-constrained retailers do not have enough initial working capital to purchase items from the manufacturer, and have to borrow money from an external bank or from the upstream manufacturer. For simplicity, we assume that the retailers' initial working capital is zero [40]. In this work, we consider three different financing methods: bank credit financing, trade credit financing, and dual-channel financing. Dual-channel financing refers to the case in which the retailers use both bank credit and trade credit. Driven by consumers' environmental awareness, the manufacturer has incentives to reduce emissions. Thus, the manufacturer's decisions are the wholesale price $w$ and emission abatement level of products $e$. Define the cost of emission abatement $h e^{2}$ $([10,13])$, where $h$ stands for the cost coefficient of emission abatement and a small $h$ implies that the manufacturer is efficient in abating emissions. In line with An et al. [4], we assume that the manufacturer has enough capital to invest in green improvement of products but has less money in production. This is because a firm needs to meet the carbon emission standards first before its normal operation. For example, the Ministry of Environmental Protection of China set a limit that enterprises that cannot reach emission reduction standard have to close in a regulated time period (http://china.cnr.cn/gdgg/20170714/t20170714_523850712. shtml). Then, when trade credit is adopted, the manufacturer has to borrow money from the bank to cover the production cost. In this work, we assume that the manufacturer's production capital is zero to focus on the financing issue ( $[31,33])$.

The sequence of events is as follows. First, the manufacturer provides the wholesale price and decides the emission abatement level. Second, the retailers borrow money from a bank, or a manufacturer, or from both and order products from the manufacturer. Third, the manufacturer borrows money from a bank if necessary and produces products by investing in emission abatement at the same time. After the demand is realized, the firms repay their debts. The relevant notation is expressed in Table 1.

Considering consumers' eco-friendly awareness, they are willing to pay higher price for green products. Then, when the retailers decide selling quantity, in line with Zhu and $\mathrm{He}$ [22], the inverse demand functions are written as

$$
\begin{aligned}
& p_{1}=v a-q_{1}-\phi q_{2}+\lambda e, \\
& p_{2}=(1-v) a-q_{2}-\phi q_{1}+\lambda e,
\end{aligned}
$$

$v$ stands for retailer 1's underlying market share, $a$ is the potential demand of the market. $\phi$ represents the substitutability of products selling by different retailers, and a larger $\phi$ implies fierce competition in the market. $\lambda$ is consumers' price sensitivity to the emission abatement level.

\section{Model Analysis}

In this section, we analyze three financing models (bank credit financing, trade credit financing, and dual channel financing) in detail. It is assumed that all the members are 
TABLE 1: Notation.

\begin{tabular}{lc}
\hline$w$ & Wholesale price charged by the manufacturer \\
$h$ & Cost coefficient of carbon emission abatement \\
$e$ & Carbon emission abatement level \\
$p_{i}$ & Retail price charged by retailer $i$ \\
$q_{i}$ & Order quantity of retailer $i$ \\
$a$ & Market size \\
$v$ & Retailer 1's underlying market share \\
$\phi$ & Substitutability of products \\
$\lambda$ & Consumers' price sensitivity to the emission abatement \\
$r_{0}$ & Basic bank interest rate \\
$\eta_{R}$ & Impact factor of bank interest rate related to retailers \\
$r_{R i}$ & The interest rate charged by the bank on retailer $i$ \\
$r_{T}$ & The interest rate charged by the manufacturer under trade \\
$r_{M}$ & The interest rate charged by the bank on the manufacturer \\
$T_{i}$ & Retailer $i$ 's loan size borrowed from the manufacturer \\
\hline
\end{tabular}

risk-neutral and seek maximized profit. Since the demand is certain and depends on the retail prices, the retailers always repay the entire loan. Otherwise, they will order nothing. Therefore, we assume that all the firms do not go bankrupt and the bank does not face firms' default risk.

4.1. Bank Credit Financing. Assume that the bank credit cost is convex in the borrowers' book leverage. The rational reasons include managerial risk aversion [42], adverse selection [43], and microeconomic foundations [44]. For simplicity, in line with Chod et al. [45], we adopt the bank credit cost by assuming that the bank interest rate increases linearly in the borrower's book leverage. Thus, the interest rate charged by the bank on the retailer over loan size $y$ is given by

$$
r_{R i}=r_{0} \eta_{R} \frac{y}{w q_{i}},
$$

$r_{0}$ is the basic bank interest rate, $\eta_{R}$ is the impact factor of bank interest rate related to the retailers. When only bank financing is adopted by retailers, the bank interest rate equals

$$
r_{R 1}=r_{R 2}=r_{0} \eta_{R} .
$$

Given the wholesale price, the retailers' expected profit are written as

$$
\begin{aligned}
& \pi_{R 1}=\left(v a-q_{1}-\phi q_{2}\right) q_{1}-w q_{1}\left(1+r_{0} \eta_{R}\right), \\
& \pi_{R 2}=\left((1-v) a-q_{2}-\phi q_{1}\right) q_{2}-w q_{2}\left(1+r_{0} \eta_{R}\right) .
\end{aligned}
$$

The next proposition fully characterizes the retailers' optimal ordering strategy when adopting bank credit financing.

Proposition 1. Under bank credit financing, the retailers' optimal order quantities are $q_{1}^{B *}=a[v(2+\phi)-\phi]-(2$ $-\phi)\left[w\left(2+r_{0} \eta_{R}\right)-\lambda e\right] / 4-\phi^{2}, q_{2}^{B *}=a[2-v(2+\phi)]-(2-$ v) $\left[w\left(2+r_{0} \eta_{R}\right)-\lambda e\right] / 4-\phi^{2}$.

Proof. Taking the first derivative of $\pi_{R 1}$ on $q_{1}$, we get

$$
\frac{\partial \pi_{R 1}}{\partial q_{1}}=-2 q_{1}+\lambda e+a v-w-\phi q_{2}-w r_{0} \eta_{R} .
$$

Taking the second derivative of $\pi_{R 1}$ on $q_{1}$, we get

$$
\frac{\partial^{2} \pi_{R 1}}{\partial q_{1}^{2}}=-2<0
$$

Thus, $\pi_{R 1}$ is concave on $q_{1}$. Similarly,

$$
\begin{aligned}
\frac{\partial \pi_{R 2}}{\partial q_{2}} & =-2 q_{2}+\lambda e+a(1-v)-w-\phi q_{1}-w r_{0} \eta_{R}, \\
\frac{\partial^{2} \pi_{R 2}}{\partial q_{2}^{2}} & =-2<0
\end{aligned}
$$

Thus, $\pi_{R 2}$ is concave on $q_{2}$.

By solving equations $\partial \pi_{R 1} / \partial q_{1}=0$ and $\partial \pi_{R 2} / \partial q_{2}=0$, denote $q_{1}^{B *}$ and $q_{2}^{B *}$ the optimal order quantities under bank credit, we can get

$$
\begin{aligned}
& q_{1}^{B *}=\frac{a[v(2+\phi)-\phi]-(2-\phi)\left[w\left(2+r_{0} \eta_{R}\right)-\lambda e\right]}{4-\phi^{2}}, \\
& q_{2}^{B *}=\frac{a[2-v(2+\phi)]-(2-v)\left[w\left(2+r_{0} \eta_{R}\right)-\lambda e\right]}{4-\phi^{2}} .
\end{aligned}
$$

Then, Proposition 1 is proved.

Proposition 1 shows that the retailers' optimal order quantities increase in an eco-friendly level. The intuition behind this result is that consumers' environmental awareness promotes them to buy green products. To meet consumers' demand, the retailers enhance their order quantity. It also shows that the optimal order quantities decrease in the wholesale price and the bank interest rate. This is because a higher wholesale price increases the retailers' ordering cost and a higher interest rate of bank credit increases the retailers' financing costs. From Proposition 1, we know that retailers can benefit from consumers' ecofriendly awareness. As a result, in practice, retailing firms can offer different kinds of items, such as low-carbon item and ordinary item, to satisfy different kinds of consumers, which may bring more profits for them.

The manufacturer's revenue $w\left(q_{1}+q_{2}\right)$ is enough to cover the production cost $c\left(q_{1}+q_{2}\right)$, so she does not to need borrow money from the bank. In this case, the manufacturer's expected profit is

$$
\pi_{M}=(w-c)\left(q_{1}+q_{2}\right)-\frac{1}{2} h e^{2} .
$$

Then, we can get the following proposition.

Proposition 2. Under bank financing, the optimal wholesale price decided by the manufacturer is $w^{B *}=a h(2+\phi)+2 c h$ $(2+\phi)\left(2+r_{0} \eta_{R}\right)-4 c \lambda^{2} / 4 h(2+\phi)\left(2+r_{0} \eta_{R}\right)-4 \lambda^{2}$, and the optimal emission abatement level is $e^{B *}=a \lambda-2 c \lambda\left(2+r_{0} \eta_{R}\right)$ $/ 2 h(2+\phi)\left(2+r_{0} \eta_{R}\right)-2 \lambda^{2}$.

Proof. Proof. Substituting $q_{1}$ and $q_{2}$ into equation (9), then taking the first derivatives, we get 


$$
\begin{aligned}
\frac{\partial \pi_{M}}{\partial w} & =\frac{a+4 c+2 \lambda e-8 w+2 r_{0} \eta_{R}(c-2 w)}{2+\phi}, \\
\frac{\partial \pi_{M}}{\partial e} & =-e h+\frac{4 \lambda(w-c)}{2+\phi} .
\end{aligned}
$$

By taking the second derivatives, we get

$$
\begin{aligned}
& \frac{\partial^{2} \pi_{M}}{\partial w^{2}}=\frac{-8-4 r_{0} \eta_{R}}{2+\phi}, \\
& \frac{\partial^{2} \pi_{M}}{\partial e^{2}}=-h, \\
& \frac{\partial^{2} \pi_{M}}{\partial e \partial w}=\frac{4 \lambda}{2+\phi},
\end{aligned}
$$

$$
\left|\begin{array}{cc}
\frac{-8-4 r_{0} \eta_{R}}{2+\phi} & \frac{4 \lambda}{2+\phi} \\
\frac{4 \lambda}{2+\phi} & -h
\end{array}\right|=\frac{h\left(8+4 r_{0} \eta_{R}\right)-16 \lambda^{2}}{(2+\phi)^{2}}>0 .
$$

Thus, $\pi_{M}$ is concave on $w$ and $e$. Let $\partial \pi_{M} / \partial w=0$ and $\partial \pi_{M} / \partial e=0$, denote $w^{B *}$ the optimal wholesale price and $e^{B *}$ the optimal carbon emission abatement level under bank financing, we get

$$
\begin{aligned}
w^{B *} & =\frac{a h(2+\phi)+2 c h(2+\phi)\left(2+r_{0} \eta_{R}\right)-4 c \lambda^{2}}{4 h(2+\phi)\left(2+r_{0} \eta_{R}\right)-4 \lambda^{2}}, \\
e^{B *} & =\frac{a \lambda-2 c \lambda\left(2+r_{0} \eta_{R}\right)}{2 h(2+\phi)\left(2+r_{0} \eta_{R}\right)-2 \lambda^{2}} .
\end{aligned}
$$

Proposition 2 shows that the wholesale price the trade credit increases in $r_{0} \eta_{R}, \lambda$ and $\mathrm{c}$, decreases in $\phi$ and $\mathrm{h}$. When the bank interest rate is high, the retailers tend to reduce the order quantity to save cost. In this case, the manufacturer charges a higher wholesale price to offset the revenue loss caused by reduced sales volume. $\lambda$ represents consumers' sensitivity of eco-friendly products, and a higher $\lambda$ means consumers are willing to pay higher price for eco-friendly products. Then, charging a higher wholesale price does not reduce the retailers' order quantity. Thus, $w$ increases in $\lambda$. Contrary to our intuition, $w$ decreases in $h . h$ implies the manufacturer capability in reducing emission, and a higher $h$ followed by a lower emission abatement level, which lowers the retailers' order quantities. To induce the retailers to order more products, the manufacturer has to provide a lower wholesale price. In conclusion, when deciding wholesale price, the manufacturer should comprehensively consider bank interest rate, market competition, and its efficiency in abating carbon emissions.

From Proposition 2, we can also find that the optimal emission abatement level increases in $\lambda$ but decreases in $r_{0} \eta_{R}, \phi, c$, and $h$. With $\lambda$ increasing, consumers are willing to pay higher price for eco-friendly products, which induce the manufacturer to invest in a higher emission abatement level. When $r_{0} \eta_{R}$ is high, the retailers have to pay more extra interest, which lowers their purchasing ability. As a result, the manufacturer has no incentive to invest in emission reduction. Thus, $e^{B *}$ decreases in $r_{0} \eta_{R}$. With $\phi$ increasing, the competition between retailers is intensified, which enhances the total order quantities. In this scenario, the manufacturer has no incentive to invest in a high emission abatement to increase sales volume. Therefore, $e^{B *}$ decreases in $\phi$. It implies that market competition hurts carbon emission reduction. To reduce more carbon emissions to meet government regulatory requirements, the manufacturer should try its best to weak competition. Obviously, either $c$ or $h$ increases the manufacturer's operating cost, so $e^{B *}$ decreases in $c$ and $h$. From the analysis, it shows that both wholesale price and emission abatement affected by interest rate were charged on the retailers. Hence, to improve carbon emission abatement level and induce retailers to order more products, it is better for the upstream-firms to cooperate with the retailers to strive for lower interest rate from banks.

Substituting $w^{B *}, e^{B *}, q_{1}^{B *}$, and $q_{2}^{B *}$ into $\pi_{R 1}, \pi_{R 2}$, and $\pi_{M}$, we can get every member's maximized profit.

$$
\begin{aligned}
& \pi_{R 1}^{B *}=\frac{\left[2 a \lambda^{2}(1-2 v)+a h(8 v+4 v \phi-3 \phi-2)\left(2+r_{0} \eta_{R}\right)-2 c h(2-\phi)\left(1+r_{0} \eta_{R}\right)\right]^{2}}{16(2-\phi)^{2}\left[h(2+\phi)\left(2+r_{0} \eta_{R}\right)-\lambda^{2}\right]^{2}} \\
& \pi_{R 2}^{B *}=\frac{\left[2 a \lambda^{2}(1-2 v)+a h(8 v+4 v \phi-6-\phi)\left(2+r_{0} \eta_{R}\right)-2 c h(2-\phi)\left(1+r_{0} \eta_{R}\right)\right]^{2}}{16(2-\phi)^{2}\left[h(2+\phi)\left(2+r_{0} \eta_{R}\right)-\lambda^{2}\right]^{2}} \\
& \pi_{M}^{B *}=\frac{h\left(a-4 c-2 c r_{0} \eta_{R}\right)^{2}}{8 h(2+\phi)\left(2+r_{0} \eta_{R}\right)-8 \lambda^{2}}
\end{aligned}
$$

4.2. Trade Credit. We now tend to see how the manufacturer and retailers make decisions when retailers adopt trade credit financing. As the retailers have more opportunities to reach terminal consumers, they can obtain more information about the market demand. Therefore, the manufacturer does not worry about the retailers' bankruptcy risk and is willing to provide the loans that the retailers need. Since the retailers' initial working capital is zero [40], the manufacturer permits retailers to pay for items at the end of the sales season, and charges retailers the extra interest rate $r_{T}$. 
According to the assumption, the manufacturer does not have capital to invest in production and borrows from a bank at an interest rate $r_{M}$. Similar to the retailers, the manufacturer confronts an interest rate that increases linearly in her total loan size $y_{M}$,

$$
r_{M}=r_{0} \eta_{M} \frac{y_{M}}{c\left(q_{1}+q_{2}\right)} \text {. }
$$

After the manufacturer announces the wholesale price and the interest rate of trade credit, the retailers order products from the manufacturer. Then, the retailers' problems are to maximize their expected profits by determining $q_{1}$ and $q_{2}$, which are described as

$$
\begin{aligned}
& \pi_{R 1}=\left(a-q_{1}-\phi q_{2}\right) q_{1}-w q_{1}\left(1+r_{T}\right), \\
& \pi_{R 2}=\left(a-q_{2}-\phi q_{1}\right) q_{2}-w q_{2}\left(1+r_{T}\right) .
\end{aligned}
$$

Then, we can get the retailers' optimal order quantities $q_{1}^{T *}=a[v(2+\phi)-\phi]-(2-\phi)\left[w\left(2+r_{T}\right)-\lambda e\right] / 4-\phi^{2}$ and $q_{2}^{T *}=a[2-v(2+\phi)]-(2-\phi)\left[w\left(2+r_{T}\right)-\lambda e\right] / 4-\phi^{2}$.

As the manufacturer's loan size is $y_{M}=c\left(q_{1}+q_{2}\right)$ in this scenario, the interest rate of bank financing on the manufacturer is $r_{M}=r_{0} \eta_{M}$. For the manufacturer, her profit consists of four parts: the sales profit that equals sales revenue minus production cost; the interest earned from trade credit; the emission abatement cost; and the bank financing cost. Then, the manufacturer's expected profit is given by

$$
\pi_{M}=(w-c)\left(q_{1}+q_{2}\right)+r_{T}\left(q_{1}+q_{2}\right)-\frac{1}{2} h e^{2}-c\left(q_{1}+q_{2}\right) r_{0} \eta_{M} .
$$

Then, we can get the next proposition that describes the manufacturer's optimal decision under trade credit financing.

Proposition 3. When the retailers use trade credit financing, the optimal wholesale price is $w^{T *}=a h(2+\phi)+2 c\left(1+r_{0}\right.$ $\left.\eta_{M}\right)\left[h(2+\phi)-2 \lambda^{2}\right] / 4\left(1+r_{T}\right)\left[h(2+\phi)-\lambda^{2}\right]$, and the optimal emission abatement level is $e^{T *}=a \lambda-2 c \lambda\left(1+r_{0}\right.$ $\left.\eta_{M}\right) / 2\left(2 h+h \phi-\lambda^{2}\right)$.

Proof. The proof is similar to Proposition 2.

Proposition 3 shows that the optimal wholesale price increases in $r_{M}$ but decreases in $r_{T}$. As bank interest rate increases the manufacturer's cost, the manufacturer tends to charge retailers higher wholesale price to cover the cost. On the other hand, the trade credit offered to retailers brings extra financing profit to the manufacturer. With $r_{T}$ increasing, the retailers' financing cost is enhanced. Thus, the manufacturer lowers the wholesale price to enlarge the retailers' demand for products. Hence, the manufacturer needs to balance trade credit interest rate charged on retailers and the wholesale price to make more profit. From Proposition 3, we can also see that the emission reduction level decreases in the coefficient of emission reduction $h$. To enhance emission abatement level, the manufacturer should find an effective way to lower coefficient $h$. The findings also show that the emission abatement level $e^{T *}$ decreases in $r_{M}$ due to the increased extra financing cost for the manufacturer. Interestingly, we find that $e^{T *}$ has nothing to do with $r_{T}$, which implies that the emission abatement level is not affected by the retailers' financial status.

By substituting $w^{T *}$ and $e^{T *}$ into $q_{1}^{T *}$ and $q_{2}^{T *}$, we can get

$$
\begin{aligned}
& q_{1}^{T *}=\frac{2 a \lambda^{2}(1-2 v)+a h(8 v+4 v \phi-3 \varphi-2)-2 c h(2-\phi)\left(1+r_{0} y_{M}\right)}{4(2-\phi)\left(2 h+h \phi-\lambda^{2}\right)}, \\
& q_{2}^{T *}=\frac{2 a \lambda^{2}(1-2 v)+a h(8 v+4 v \phi-\phi-6)-2 c h(2-\phi)\left(1+r_{0} y_{M}\right)}{4(2-\phi)\left(2 h+h \phi-\lambda^{2}\right)}
\end{aligned}
$$

The forms of order quantities show that the retailers' final optimal order quantity is immune to the trade credit interest rate $r_{T}$. This is because the manufacturer has to lower the wholesale price when charging a higher interest rate $r_{T}$. The side negative effect of charging a higher $r_{T}$ is offset by the positive effect of a lower wholesale price. As a result, the optimal order quantities are not affected by the interest rate $r_{T}$. It also shows that the optimal order quantities decrease in the bank interest $r_{M}$ due to the increased wholesale price caused by the manufacturer's bank financing.

By substituting $w^{T *}, e^{T *}, q_{1}^{T *}$, and $q_{2}^{T *}$ into $\pi_{R 1}, \pi_{R 2}$, and $\pi_{M}$, we can get each participator's optimal expected profit under trade credit:

$$
\begin{aligned}
& \pi_{R 1}^{T *}=\frac{\left[2 a \lambda^{2}(1-2 v)+a h(8 v+4 v \phi-3 \phi-2)-2 c h(2-\phi)\left(1+r_{0} y_{M}\right)\right]^{2}}{16(2-\phi)^{2}\left(2 h+h \phi-\lambda^{2}\right)^{2}}, \\
& \pi_{R 2}^{T *}=\frac{\left[2 a \lambda^{2}(1-2 v)+a h(8 v+4 v \phi-\phi-6)-2 c h(2-\phi)\left(1+r_{0} y_{M}\right)\right]^{2}}{16(2-\phi)^{2}\left(2 h+h \phi-\lambda^{2}\right)^{2}},
\end{aligned}
$$




$$
\pi_{M}^{T *}=\frac{h\left(a-2 c-2 c r_{0} \eta_{M}\right)^{2}}{8 h(2+\phi)-8 \lambda^{2}} .
$$

From equations (18)-(20), we find that the trade credit interest rate does not affect all the members' profit when the retailers use trade credit financing.

By comparing the equilibriums under bank credit and trade credit, the following proposition holds.

Proposition 4. Trade credit can bring in more profits for all the supply chain members and contributes more to environmental protection, i.e., $q_{i}^{T *}>q_{i}^{B *}, \quad e_{i}^{T *}>e_{i}^{B *}$, $w_{i}^{T *}<w_{i}^{B *}, \pi_{R i}^{T *}>\pi_{R i}^{B *}$, and $\pi_{M}^{T *}>\pi_{M}^{B *}$.

Proof.

(a) By solving $q_{i}^{T *}-q_{i}^{B *}=0$, we get $\eta_{M 1}=$ (1+ $\left.r_{0} \eta_{R}\right)\left(a \lambda^{2}+2 c h(2+\phi)\left(2+r_{0} \eta_{R}\right)-3 c \lambda^{2}\left(1+r_{0} \eta_{R}\right)\right)$ $/ 2 c r_{0}\left(h(2+\phi)\left(2+r_{0} \eta_{R}\right)-\lambda^{2}\right)$. Then, $r_{M 1}=((1+$ $\left.r_{0} \eta_{R}\right)\left(a \lambda^{2}+2 c h(2+\phi)\left(2+r_{0} \eta_{R}\right)-3 c \lambda^{2}\left(1+r_{0} \eta_{R}\right)\right)$ $\left./ 2 c\left(h(2+\phi)\left(2+r_{0} \eta_{R}\right)-\lambda^{2}\right)\right)>1+r_{0} \eta_{R}$

When $r_{M}=r_{M 1}, q_{1}^{B *}=q_{1}^{T *}$. As $q_{1}^{T *}$ decreases in $r_{M}$, so $q_{1}^{T *}>q_{1}^{B *}$ when $r_{M}<1$.

In a similar way, we can prove $e_{i}^{T *}>e_{i}^{B *}$, $w_{i}^{T *}<w_{i}^{B *}, \pi_{R i}^{T *}>\pi_{R i}^{B *}$, and $\pi_{M}^{T *}>\pi_{M}^{B *}$.

(b) Comparing the numerators of $e_{i}^{T *}$ and $e_{i}^{B *}$, we find that the numerator of $e_{i}^{T *}$ is larger than that of $e_{i}^{B *}$. Comparing the denominators of the two expressions, we find denominator of $e_{i}^{T *}$ is smaller than that of $e_{i}^{B *}$. Thus, $e_{i}^{T *}>e_{i}^{B *}$.

(c) $w^{T *}=\left(a h(2+\phi)+2 c\left(1+r_{0} \eta_{M}\right)\left[h(2+\phi)-2 \lambda^{2}\right] / 4\right.$ $\left.\left(1+r_{T}\right)\left[h(2+\phi)-\lambda^{2}\right]\right)<\left(a h(2+\phi)+2 c\left(1+r_{0} \eta_{R}\right.\right.$ )$\left.\left[h(2+\phi)-2 \lambda^{2}\right] / 4\left[h(2+\phi)-\lambda^{2}\right]\right), w_{i}^{B *}-(a h(2+$ $\left.\phi)+2 c\left(1+r_{0} \eta_{R}\right)\left[h(2+\phi)-2 \lambda^{2}\right] / 4\left[h(2+\phi)-\lambda^{2}\right]\right)$ $>0$.

So $w_{i}^{T *}<w_{i}^{B *}$

(d) Taking the first derivative of $\pi_{R 1}^{T *}$ on $r_{M}$, we get

$$
\frac{\partial \pi_{R 1}^{T *}}{\partial r_{M}}=\frac{c h r_{0}}{2\left(h(2+\phi)-\lambda^{2}\right)}>0 .
$$

$$
\text { So } \pi_{R 1}^{T *} \text { increases in } r_{M} \text {. }
$$

By solving $\pi_{R 1}^{T *}-\pi_{R 1}^{B *}=0$, we get $\eta_{M 2}=(1+$ $\left.r_{0} \eta_{R}\right)\left(a \lambda^{2}+2 c h(2+\phi)\left(2+r_{0} \eta_{R}\right)-2 c \lambda^{2}\left(3+r_{0} \eta_{R}\right)\right)$ $/ 2 c r_{0}\left(h(2+\phi)\left(2+r_{0} \eta_{R}\right)-\lambda^{2}\right)$.

Then, $r_{M 2}=\left(\left(1+r_{0} \eta_{R}\right)\left(a \lambda^{2}+2 c h(2+\phi)\left(2+r_{0} \eta_{R}\right.\right.\right.$ )$\left.\left.-2 c \lambda^{2}\left(3+r_{0} \eta_{R}\right)\right) / 2 c\left(h(2+\phi)\left(2+r_{0} \eta_{R}\right)-\lambda^{2}\right)\right)>1$ $+r_{0} \eta_{R}$.

so $\pi_{R 1}^{T *}>\pi_{R 1}^{B *}$ when $r_{M}<1$.

In a similar way, we can prove $\pi_{R 2}^{T *}>\pi_{R 2}^{B *}$, and $\pi_{M}^{T *}>\pi_{M}^{B *}$.

Proposition 4 shows that each member of the supply chain can make more profit under trade credit. The managerial insight we can get from this proposition is that offering financial assistance is an effective way for firms to earn more profit. As a result, when the retailers have no access for borrowing money from external financing, it is better for the manufacturer to offer trade credit to the downstream partners. On the other hand, Proposition 4 also shows that the emission abatement level under trade credit is higher than that under bank credit, which implies that trade credit contributes more in curbing carbon emissions. In addition, both retailers' order quantities under trade credit are greater than those under bank credit. It implies that trade credit brings more items for consumers and enlarges consumption. This finding shows that it is a better choice for all the supply chain members to use trade credit. Therefore, the upstream firms should try their best to offer trade credit to downstream firms to earn more profits. To promote the development of enterprises and reduce carbon emissions more effectively, governments can promulgate policy to encourage firms to use trade credit.

4.3. Dual Financing Channel. We now turn to the scenario in which the retailers adopt both trade credit financing and bank credit financing at the same time. Because the cost of the first dollar of bank financing is zero, the retailers use bank financing first. With the increasing marginal cost of bank credit, the retailers tend to use trade credit once the marginal cost of bank financing equals the trade credit interest rate charged by the manufacturer. In this scenario, the retailers decide the order quantity and the loan size of each financing channel. Assuming retailer is loan size borrowed from the manufacturer is $T_{i}$, then, the loan size of bank credit is $\left(w q_{i}-T_{i}\right)$. The interest rate of bank credit is

$$
r_{R i}=r_{0} \eta_{R} \frac{w q_{i}-T_{i}}{w q_{i}}
$$

Given the wholesale price and the interest rates, the retailers' profits consist of two parts: the operating profit and the financing cost, which are expressed as follows:

$$
\begin{aligned}
& \pi_{R 1}=\left(a-q_{1}-\phi q_{2}-w\right) q_{1}-\frac{\left(w q_{1}-T_{1}\right)^{2} r_{0} \eta_{R}}{w q_{1}}-T_{1} r_{T}, \\
& \pi_{R 2}=\left(a-q_{2}-\phi q_{1}-w\right) q_{2}-\frac{\left(w q_{2}-T_{2}\right)^{2} r_{0} \eta_{R}}{w q_{2}}-T_{2} r_{T} .
\end{aligned}
$$

By solving the retailers' maximizing problem, we can get the following proposition.

Proposition 5. When both trade credit and bank credit are used by the retailers, the optimal order quantities are $q_{1}^{T B} *=$ $r_{T}^{2} w(2-\phi)+4 r_{0} \eta_{R}\left[2 a v+\lambda e(2-\phi)-w\left(1+r_{T}\right)(2-\phi)-a\right.$ $\phi(1-v)] / 4 r_{0} \eta_{R}\left(4-\phi^{2}\right)$ and $q_{2}^{T B *}=r_{T}^{2} w(2-\phi)+4 r_{0} \eta_{R}$ $\left[\lambda e(2-\phi)-w\left(1+r_{T}\right)(2-\phi)+a(2-2 v-v \phi)\right] / 4 r_{0} \eta_{R}(4-$ 
$\left.\phi^{2}\right)$. The optimal loan sizes of trade credit are $T_{1}^{*}$ $=w q_{1}^{T B *}\left(2 r_{0} \eta_{R}-r_{T}\right) / 2 r_{0} \eta_{R}$ and $T_{2}^{*}=w q_{2}^{T B *}\left(2 r_{0} \eta_{R}-r_{T}\right)$ $/ 2 r_{0} \eta_{R}$.

Proof. By taking the first derivatives, we can get

$$
\begin{aligned}
& \frac{\partial \pi_{R 1}}{\partial q_{1}}=-2 q_{1}+\lambda e+a v-w-\phi q_{2}-w r_{0} \eta_{R}+\frac{r_{0} \eta_{R} T_{1}^{2}}{w q_{1}^{2}} \\
& \frac{\partial \pi_{R 1}}{\partial T_{1}}=-r_{T}+\frac{2 r_{0} \eta_{R}\left(w q_{1}-T_{1}\right)}{w q_{1}}, \\
& \frac{\partial \pi_{R 2}}{\partial q_{2}}=-2 q_{2}+\lambda e+a(1-v)-w-\phi q_{1}-w r_{0} \eta_{R}+\frac{r_{0} \eta_{R} T_{2}^{2}}{w q_{2}^{2}}, \\
& \frac{\partial \pi_{R 2}}{\partial T_{2}}=-r_{T}+\frac{2 r_{0} \eta_{R}\left(w q_{2}-T_{2}\right)}{w q_{2}} .
\end{aligned}
$$

By taking the second derivatives, we can get

$$
\begin{aligned}
& \frac{\partial^{2} \pi_{R 1}}{\partial q_{1}^{2}}=-2-2 \frac{r_{0} \eta_{R} T_{1}^{2}}{w q_{1}^{3}}, \\
& \frac{\partial^{2} \pi_{R 1}}{\partial T_{1}^{2}}=-2 \frac{r_{0} \eta_{R}}{w q_{1}} .
\end{aligned}
$$

Thus, $\pi_{R 1}$ is concave on $q_{1}$ and $T_{1}$.

$$
\begin{aligned}
& \frac{\partial^{2} \pi_{R 2}}{\partial q_{2}^{2}}=-2-2 \frac{r_{0} \eta_{R} T_{2}^{2}}{w q_{2}^{3}}, \\
& \frac{\partial^{2} \pi_{R 2}}{\partial T_{2}^{2}}=-2 \frac{r_{0} \eta_{R}}{w q_{2}} .
\end{aligned}
$$

Thus, $\pi_{R 2}$ is concave on $q_{2}$ and $T_{2}$.

By solving the equations $\partial \pi_{R 1} / \partial q_{1}=0, \partial \pi_{R 1} / \partial T_{1}=0$, $\partial \pi_{R 2} / \partial q_{2}=0$, and $\partial \pi_{R 2} / \partial T_{2}=0$, we can get $q_{1}^{T B *}=r_{T}^{2} w(2-$ $\phi)+4 r_{0} \eta_{R}\left[2 a v+\lambda e(2-\phi)-w\left(1+r_{T}\right)(2-\phi)-a \phi(1-v)\right.$ ]$/ 4 r_{0} \eta_{R}\left(4-\phi^{2}\right), \quad q_{2}^{T B *}=r_{T}^{2} w(2-\phi)+4 r_{0} \eta_{R}[\lambda e(2-\phi)-$ $\left.w\left(1+r_{T}\right) \quad(2-\phi)+a(2-2 v-v \phi)\right] / 4 r_{0} \eta_{R}\left(4-\phi^{2}\right), \quad T_{1}^{*}=$ $w q_{1}^{T B *}\left(2 r_{0} \eta_{R}-r_{T}\right) / 2 r_{0} \eta_{R}, T_{2}^{*}=w q_{2}^{T B *}\left(2 r_{0} \eta_{R}-r_{T}\right) / 2 r_{0} \eta_{R}$.

Proposition 5 demonstrates the retailers' optimal decisions under dual-channel financing. It shows that the order quantities decrease in interest rate and the bank credit interest rate. This is because financing cost directly increases the retailers' operating cost. As for the loan size of trade credit, it highly depends on the interest rate charged by the manufacturer and that charged by the bank. The form of $T_{i}$ shows that when $r_{T} \geq 2 r_{0} \eta_{R}$, the retailers will not borrow from the manufacturer. When $r_{T}<2 r_{0} \eta_{R}$, the retailers borrow from the manufacturer and the bank. Specifically, if $r_{T}=r_{0} \eta_{R}$, the retailers borrow the same loan size under the two financing channels; if $r_{T}<r_{0} \eta_{R}$, the retailers borrow more money from the manufacturer. The result shows that even if the trade credit interest rate is smaller than the bank interest rate, the retailers still borrow from the bank. From Proposition 4, we know that trade credit can bring more profit to a manufacturer. Thus, retailers can use trade credit to maintain a long-term and stable partnership with the manufacturer. These findings imply that when both financing channels are available, firms should properly allocate the loan amount upon trade credit and bank credit, so as to minimize the loan cost and maximize the profit.

Anticipating the retailers' optimal order quantities $q_{1}^{T B *}$, $q_{2}^{T B *}$ and the loan size of trade credit $T_{1}^{*}+T_{2}^{*}$, the manufacturer chooses the optimal wholesale price and emission abatement level to maximize her expected profit. In this scenario, the loan size borrowed from the bank by the manufacturer is $\left[c\left(q_{1}+q_{2}\right)-w\left(q_{1}+q_{2}\right)+T_{1}+T_{2}\right]$. Thus, the manufacturer's expected profit can be written as

$$
\begin{aligned}
\pi_{M}= & (w-c)\left(q_{1}+q_{2}\right)+r_{T}\left(T_{1}+T_{2}\right) \\
& -\frac{1}{2} h e^{2}-\left[c\left(q_{1}+q_{2}\right)-w\left(q_{1}+q_{2}\right)+T_{1}+T_{2}\right] r_{0} \eta_{M} .
\end{aligned}
$$

Then, we can get the following conclusion that describes the manufacturer's optimal decision under dual-channel financing.

Proposition 6. Under dual-channel financing, the optimal wholesale price offered by the manufacturer is $w^{T B *}=\left(-r_{0} \eta_{R} a h(2+\phi)+2 c \lambda^{2}\left(1+r_{0} \eta_{M}\right) / D\right)-\left(c\left(1+r_{0}\right.\right.$ $\left.\eta_{M}\right) / A$ ), and increases in $r_{M}$ but decreases in $r_{T}$ and $r_{R}$, where $r_{R}=r_{0} \eta_{R}, \quad r_{M}=r_{0} \eta_{M}, \quad A=r_{T}\left(r_{T}-r_{0} \eta_{M}\right)-2 r_{R}\left(1+r_{T}\right)$, and $D=h(2+\phi)\left(r_{T}^{2}-4 r_{R}\left(1+r_{T}\right)\right)+2 \lambda^{2}\left(r_{T}\left(r_{0} \eta_{M}-r_{T}\right)\right.$ $\left.+2 r_{0} \eta_{R}\left(1+r_{T}\right)\right)$. The optimal emission abatement level is $e^{T B *}=\lambda r_{T}\left(a r_{0} \eta_{M}-a r_{T}+c r_{T}+c r_{T} r_{0} \eta_{M}\right)+2 r_{0} \eta_{R} \lambda(1+$ $\left.r_{T}\right)\left(a-2 c-2 c r_{0} \eta_{M}\right) /-D$, and it increases in $r_{M}$ but decreases in $\phi$. If $r_{T}>2 r_{M}, e^{T B *}$ increases in $r_{R}$; if $r_{T}<2 r_{M}, e^{T B *} d e-$ creases in $r_{R}$. If $r_{M}>\left(2 r_{T} r_{R}\left(2+r_{T}\right) / r_{T}^{2}+4 r_{R}\right)$, $e^{T B *}$ increases in $r_{T}$; if $r_{M}<\left(2 r_{T} r_{R}\left(2+r_{T}\right) / r_{T}^{2}+4 r_{R}\right), \quad e^{T B *}$ decreases in $r_{T}$.

Proof. Substituting $q_{1}^{T B *}$ and $q_{2}^{T B *}$ into equation (27), then taking the first derivative of on $w$ and $e$, we can get

$$
\begin{aligned}
\frac{\partial \pi_{M}}{\partial w}= & \frac{r_{T}^{3} w\left(r_{0} \eta_{M}-r_{T}\right)-r_{0} \eta_{R} r_{T}\left(r_{T}\left(a+c+2 \lambda e-6\left(1+r_{T}\right) w\right)\right)}{2 r_{0}^{2} \eta_{R}^{2}(2+\phi)} \\
& +\frac{\left.r_{0} \eta_{R}\left(-a+c r_{T}-2 \lambda e+4\left(1+r_{T}\right) w\right) \eta_{M}\right)\left(1+r_{T}\right)\left(a+2\left(c+\lambda e-2\left(1+r_{T}\right) w+c r_{0} \eta_{M}\right)\right)}{2 r_{0}^{2} \eta_{R}^{2}(2+\phi)}
\end{aligned}
$$




$$
\frac{\partial \pi_{M}}{\partial e}=\frac{r_{T} \lambda w\left(r_{0} \eta_{M}-r_{T}\right)-r_{0} \eta_{R}\left(e h(2+\phi)+2 \lambda\left(c-w\left(1+r_{T}\right)+c r_{0} \eta_{M}\right)\right)}{(2+\phi) r_{0} \eta_{R}} .
$$

By taking the second derivatives, we can get

$$
\begin{aligned}
\frac{\partial^{2} \pi_{M}}{\partial w^{2}}= & \frac{r_{T}^{3} w\left(r_{0} \eta_{M}-r_{T}\right)-r_{0} \eta_{R} r_{T}\left(4 r_{0} \eta_{M}-6 r_{T}\right)\left(1+r_{T}\right)-8\left(1+r_{T}\right) r_{0}^{2} \eta_{R}^{2}}{2 r_{0}^{2} \eta_{R}^{2}(2+\phi)}, \\
\frac{\partial^{2} \pi_{M}}{\partial e^{2}}= & -h, \\
\frac{\partial^{2} \pi_{M}}{\partial w \partial e}= & \frac{\lambda\left(-r_{T}^{2}+2 r_{0} \eta_{R}+r_{0} r_{T}\left(\eta_{M}+2 \eta_{R}\right)\right)}{r_{0} \eta_{R}(2+\phi)}, \\
& \cdot\left|\begin{array}{ll}
\frac{\partial^{2} \pi_{M}}{\partial w^{2}} & \frac{\partial^{2} \pi_{M}}{\partial w \partial e} \\
\frac{\partial^{2} \pi_{M}}{\partial w \partial e} & \frac{\partial^{2} \pi_{M}}{\partial e^{2}}
\end{array}\right|>0 .
\end{aligned}
$$

Thus, $\pi_{M}$ is concave on $w$ and $e$. Let $\partial \pi_{M} / \partial w=0$ and $\partial \pi_{M} / \partial e=0$ denote $w^{T B *}$ the optimal wholesale price and
$e^{T B *}$ the optimal carbon emission abatement level under bank financing, we get

$$
\begin{aligned}
w^{T B *} & =\frac{-r_{0} \eta_{R} a h(2+\phi)+2 c \lambda^{2}\left(1+r_{0} \eta_{M}\right)}{D}-\frac{c\left(1+r_{0} \eta_{M}\right)}{A}, \\
e^{T B *} & =\frac{\lambda r_{T}\left(a r_{0} \eta_{M}-a r_{T}+c r_{T}+c r_{T} r_{0} \eta_{M}\right)+2 r_{0} \eta_{R} \lambda\left(1+r_{T}\right)\left(a-2 c-2 c r_{0} \eta_{M}\right)}{-D}, \\
\frac{\partial e}{\partial r_{T}} & =\frac{\lambda r_{0}\left(a h(2+\phi)-2 c \lambda^{2}\left(1+r_{0} \eta_{M}\right)\right)\left(r_{T}^{2} \eta_{M}-2 r_{T}\left(2+r_{T}\right) \eta_{R}+4 r_{0} \eta_{M} \eta_{R}\right)}{h(2+\phi)\left(r_{T}^{2}-4 r_{0} \eta_{R}\left(1+r_{T}\right)\right)+2 \lambda^{2}\left(\left(r_{0} \eta_{M}-r_{T}\right) r_{T}+2 r_{0} \eta_{R}\left(1+r_{T}\right)\right)^{2}} .
\end{aligned}
$$

By solving $r_{T}^{2} \eta_{M}-2 r_{T}\left(2+r_{T}\right) \eta_{R}+4 r_{0} \eta_{M} \eta_{R}=0$, we get $r_{M}=2 r_{T} r_{R}\left(2+r_{T}\right) / r_{T}^{2}+4 r_{R}$. When $r_{M}>2 r_{T} r_{R}\left(2+r_{T}\right)$ $/ r_{T}^{2}+4 r_{R}$, $\partial e / \partial r_{T}>0$; when $r_{M}<\left(2 r_{T} r_{R}\left(2+r_{T}\right) / r_{T}^{2}+4 r_{R}\right)$, $\partial e / \partial r_{T}<0$.

Then, Proposition 6 is proved.

When retailers adopt both bank financing and trade credit, the wholesale price and the emission abatement level decided by the manufacturer highly depend on the bank credit interest rate charged on retailers and the trade credit interest rate. It shows that the wholesale price increases in $r_{M}$ but decreases in $r_{T}$ and $r_{R}$. As the manufacturer does not have enough capital to invest in producing, she borrows from the bank. With $r_{M}$ increasing, the financing cost of the manufacturer increases. To offset the financing cost, the manufacturer tends to charge a higher wholesale price to increase the sales revenue. Under dual-channel financing, the manufacturer should also pay attention to the bank interest rate charged on retailers. When bank charges a higher interest rate on retailers, the manufacturer should lower the wholesale price to promote retailers to order more products.

Interestingly, we find that the optimal emission abatement level increases in $r_{M}$. As we know, a larger $r_{M}$ increases the manufacturer's financial cost. To cover the increased cost, the manufacturer either sets a higher wholesale price or promotes the sales volume. Given that the consumers are eco-friendly aware, the manufacturer chooses to invest in a higher emission abatement level to increase the market demand, whereas when $\phi$ is large, it implies that the competition between retailers is fierce, which lowers the retail prices. In this case, the marginal profit of the manufacturer is reduced. To save the operating cost, the manufacturer sets a lower emission abatement level. The relationship between $e^{T B *}$ and $r_{T}$ and $r_{R}$ is not conclusive. When $r_{T}$ is relatively large, i.e., $r_{T}>2 r_{M}$, the financial profit earned from the retailers is larger than the financial cost paid 
to the bank. With a larger bank interest rate $r_{R}$, the retailers' profits decrease. To maintain the retailers' normal operation, the manufacturer has incentive to invest in a higher emission abatement level to increase the retail prices. When $r_{M}>\left(2 r_{T} r_{R}\left(2+r_{T}\right) / r_{T}^{2}+4 r_{R}\right)$, the financial cost exceeds the financing profit for the manufacturer. In this scenario, the manufacturer is better off by charging a higher trade credit interest rate. However, the retailers are worse off due to the increased financial cost. To drive retailers to order more products, the manufacturer is willing to invest in a higher emission abatement level. Thus, there exits $e^{T B *}$ increases in $r_{T}$ when $r_{M}>\left(2 r_{T} r_{R}\left(2+r_{T}\right) / r_{T}^{2}+4 r_{R}\right)$. Under carbon emission regulation, if the bank interest rate is relatively large, firms either charge a higher interest rate on the borrowers to guarantee carbon emissions meeting the requirements or they can charge a higher wholesale price to increase revenue and use it to buy carbon emission permits in the carbon trading market.

Proposition 7. If $r_{T}<2 r_{M}$, there exits $e^{T B *}>e^{T *}$; if $r_{T}>2 r_{M}$, there exits $e^{T B *}<e^{T *}$.

Proposition 7 demonstrates the relationship of the optimal emission abatement levels under different financial channels. It shows that when $r_{T}$ is relatively small, i.e., $r_{T}<2 r_{M}$, the emission abatement level under dual-channel financing is larger. In this scenario, bank credit is not only a possible way to finance capital-constrained firms but also helps to control the emission abatement level and brings more environmental benefit. When $r_{T}$ is relatively large, trade credit contributes more in abating carbon emissions than dual-channel financing. The managerial insight behind this result is that choosing an appropriate financing way can not only solve the financing difficulties of enterprises but also help to control carbon emissions.

As the forms of the wholesale price and each member's profit under dual-channel financing are too complicated, we compare them with single-channel financing in the numerical experiment section.

Proof. $e^{T B *}-e^{T *}=\lambda r_{T}\left(r_{T}-2 r_{0} \eta_{M}\right)\left(a h(2+\phi)-2 c \lambda^{2}(1+\right.$ $\left.\left.r_{0} \eta_{M}\right)\right) / 2\left(h(2+\phi)-\lambda^{2}\right) \quad\left(h(2+\phi)\left(r_{T}^{2}-4 r_{0} \eta_{R}\left(1+r_{T}\right)\right)+2\right.$ $\left.\lambda^{2}\left(\left(r_{0} \eta_{M}-r_{T}\right) r_{T}+2 r_{0} \eta_{R}\left(1+r_{T}\right)\right)\right)$. Thus, when $r_{T}<2 r_{M}$, $e^{T B *}>e^{T *}$; when $r_{T}>2 r_{M}, e^{T B *}<e^{T *}$.

\section{Numerical Experiment}

In this section, we tend to perform several sets of numerical experiments to illustrate the managerial insight that resulted from this work. We set $a=300, v=0.6, r_{0}=0.05, c=10$, $h=2000, \eta_{R}=1, \eta_{M}=1.5\left(\eta_{M}\right.$ is variable when we investigate the impact of bank interest on the manufacturer), $\phi=$ 0.3 ( $\phi$ is variable when examining the impact of competition), $\lambda=5$ ( $\lambda$ is variable when examining the impact of consumers' sensitivity on eco-friendly products), $r_{T}=0.05$ $\left(r_{T}\right.$ is variable when discussing the allocation of loan size of different kinds of financing).

The first set of numerical examples demonstrates the impacts of consumers' sensitivity on eco-friendly product $\lambda$.
From Figure 1 we can see that the manufacturer can charge a high wholesale price when consumers are very sensitive to low-carbon products. This is because consumers are willing to pay higher price for the low-carbon items. Hence, providing a high wholesale price does not affect the retailers' order willingness. On the other hand, if consumers pay much more attention to eco-friendly awareness, the manufacturer also has incentive to invest in a high emission abatement level to promote sales volume. Thus, the carbon emission abatement level $e$ increases in $\lambda$, which is shown in Figure 2. It means that consumers' environmental awareness plays a significant role in curbing carbon emissions in the world.

The impacts of $\lambda$ on the retailers' order quantity are shown in Figures 3 and 4 . As can be seen, both retailers' order quantities increase in $\lambda$ regardless of using any kind of financing methods. It implies that consumers' eco-friendly awareness enhances the demand for low-carbon products. From Figures 3 to 4 , we can also see that $q_{1}^{T B}>q_{1}^{T}>q_{1}^{B}$ and $q_{2}^{T B}>q_{2}^{T}>q_{2}^{B}$. It means that the retailers order the most quantities when using dual-financing channels and they order the least order quantities when using bank credit financing.

Figures 5-7 depict the impact of $\lambda$ on each supply chain member's profit. As we can see, each member's profit increases in $\lambda$. It shows that abating carbon emission is not only a way to protect the environment but also an effective way to increase firms' revenue. Therefore, under the background of low-carbon economy, abating carbon emissions is a good way for firms to maintain sustainable development. On the other hand, Figures 5-7 also show that each member makes the most profit under dual-financing channel and makes the least profit under bank credit financing. It proves that trade credit is better than bank credit for all the supply chain members. If both trade credit and bank credit are available to capital-constrained firms, using dual-financing methods is the best choice.

This set of numerical experiments illustrates how competition affects each member's decision and profit. The wholesale price under bank credit financing is relatively small, and it is difficult to show the impact of $\phi$ on $w$ when drawing $w^{T}, w^{B}$, and $w^{T B}$ in one picture. Thus, we ignore $w^{B}$ in this case. As shown in Figure 8, intensified competition lowers the wholesale price. We know that the prices of products reduce due to competition. Then, the marginal profit of retailers is lowered. In this case, charging a higher wholesale price hurts retailers' order incentive. As a result, $w$ decreases in $\phi$. In this scenario, the manufacturer does not have incentive to invest in high emission abatement level. Thus, $e$ decreases in $\phi$, which is shown in Figure 9. It implies that competition is bad for carbon emission abatement.

In Figure 10, it is interesting to note that retailer 1's order quantity decreases in $\phi$ first but increases in $\phi$ when the order quantity reaches the lowest point. With the competition intensity increases, the price of products sold by retailer 1 decreases. In this case, retailer 1 tends to reduce the order quantity to avoid revenue loss. Whereas when $\phi$ is much higher, retailer 1 can make more profit by selling more products. For retailer 2 , the market share is very small and he 


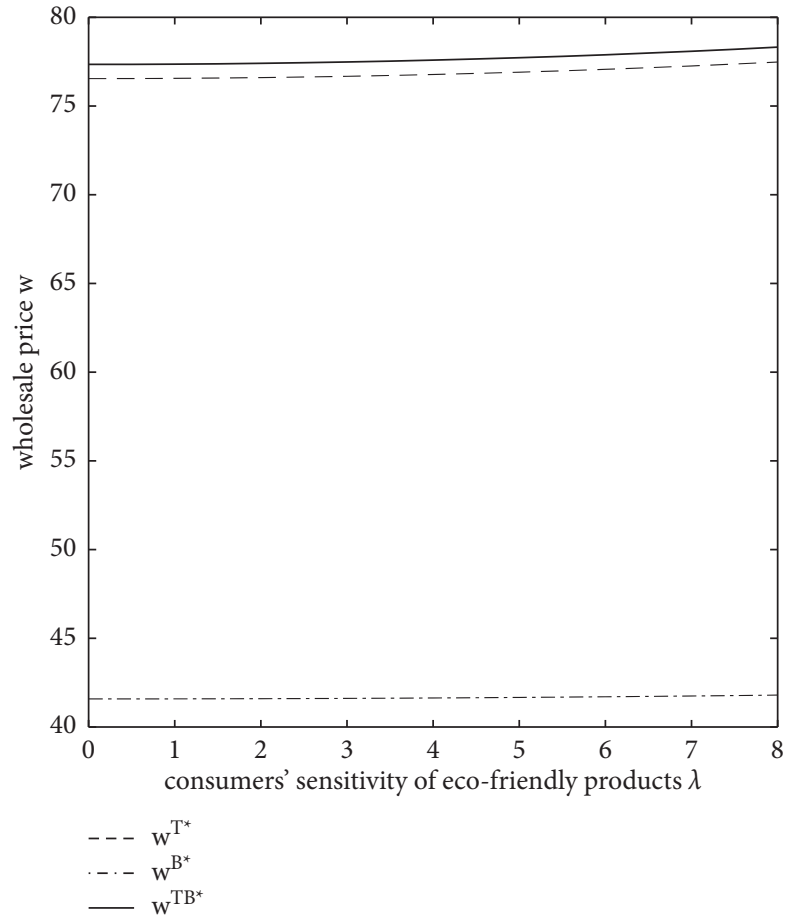

Figure 1: Impact of $\lambda$ on $w$.

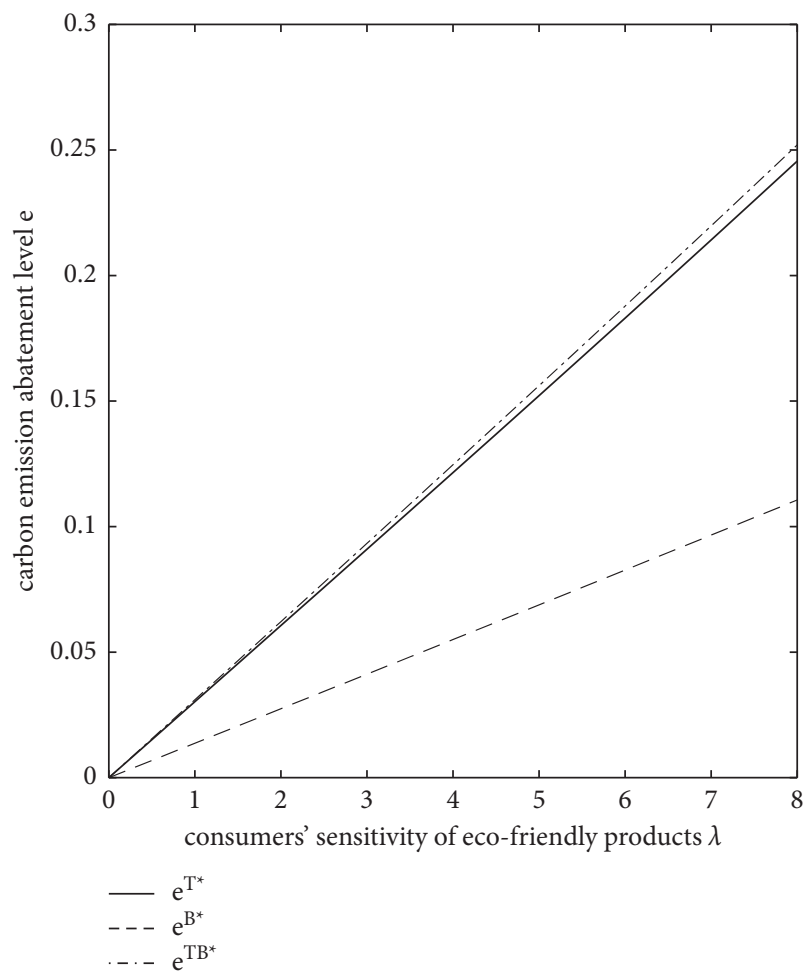

FIgURE 2: Impact of $\lambda$ on $e$.

does not have competitive advantage. Thus, retailer 2's order quantity decreases in $\phi$ all the time, which is shown in Figure 11.

Based on the impacts of $\phi$ on the retailers' order quantity and wholesale price, we can easily get to know the the

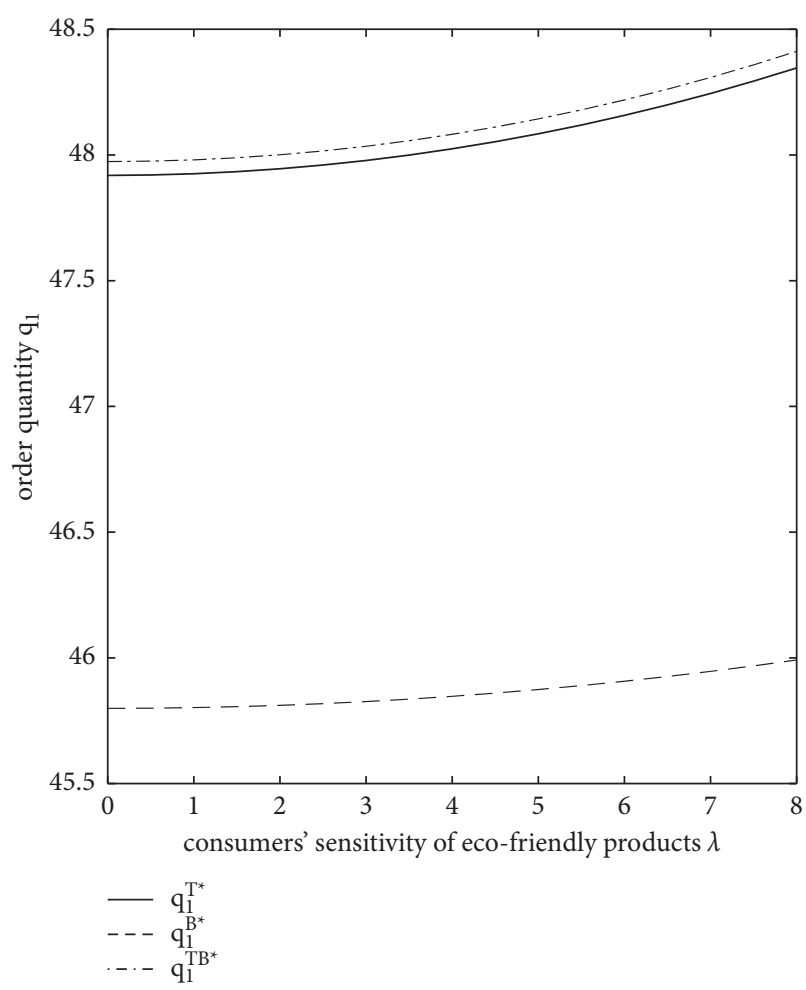

Figure 3: Impact of $\lambda$ on $q_{1}$.

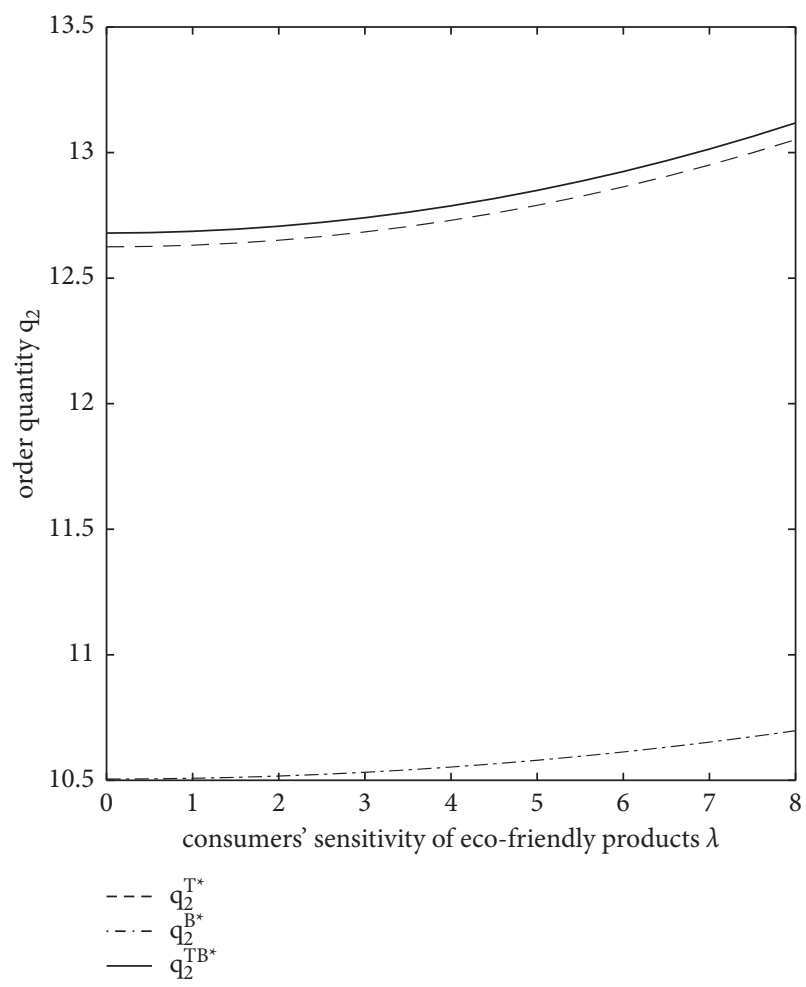

Figure 4: Impact of $\lambda$ on $q_{2}$.

relationship between retailer 1's profit $\pi_{R 1}$ and $\phi$ is an inverse- $U$ shape, as shown in Figure 12. The profits of both retailer 2 and the manufacturer decrease in $\phi$, which are 


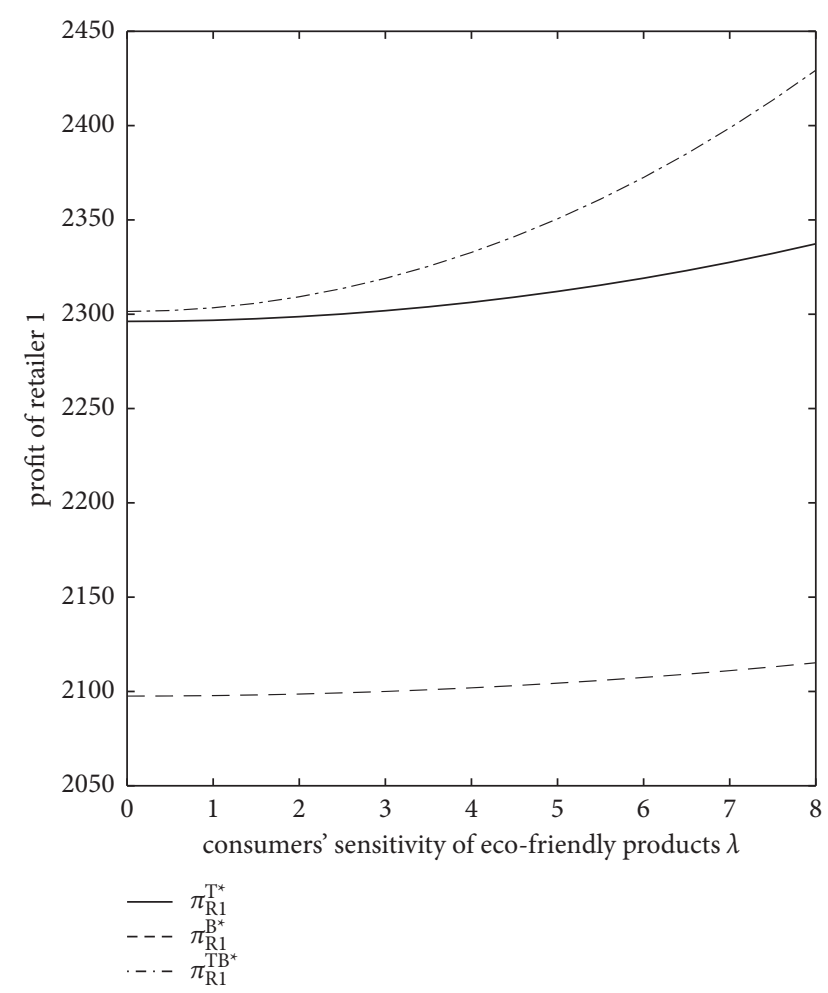

FIgURE 5: Impact of $\lambda$ on $\pi_{R 1}$.

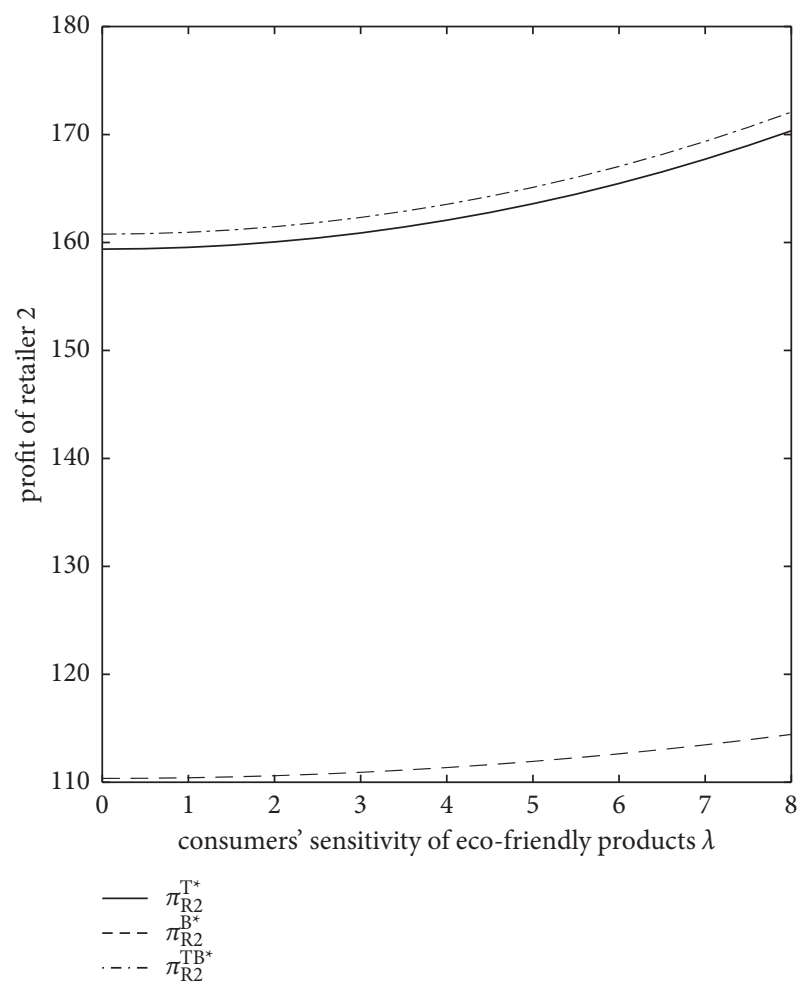

FIgURE 6: Impact of $\lambda$ on $\pi_{R 2}$.

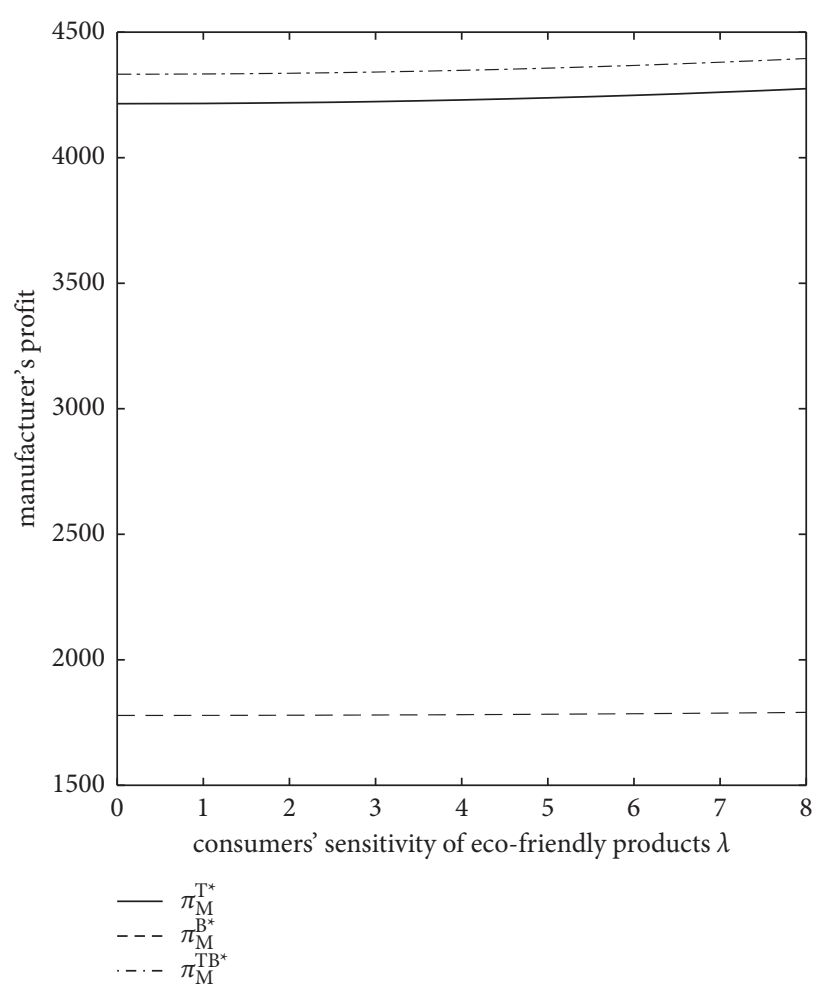

Figure 7: Impact of $\lambda$ on $\pi_{M}$.

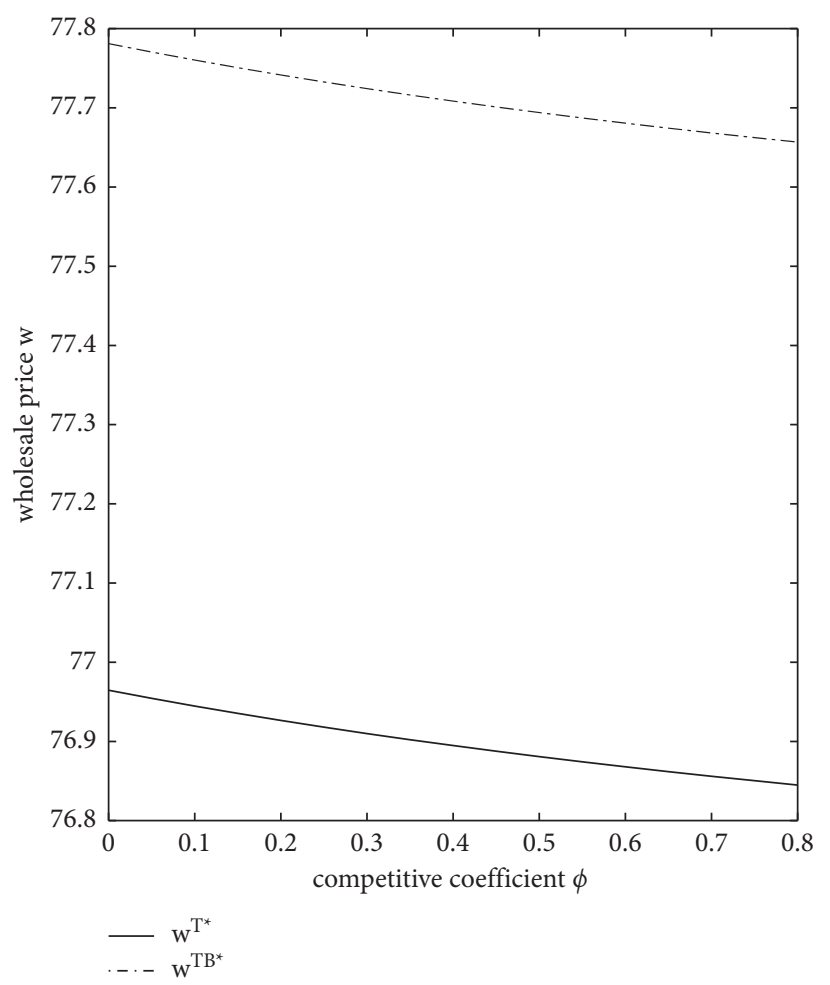

Figure 8: Impact of $\phi$ on $w$. 


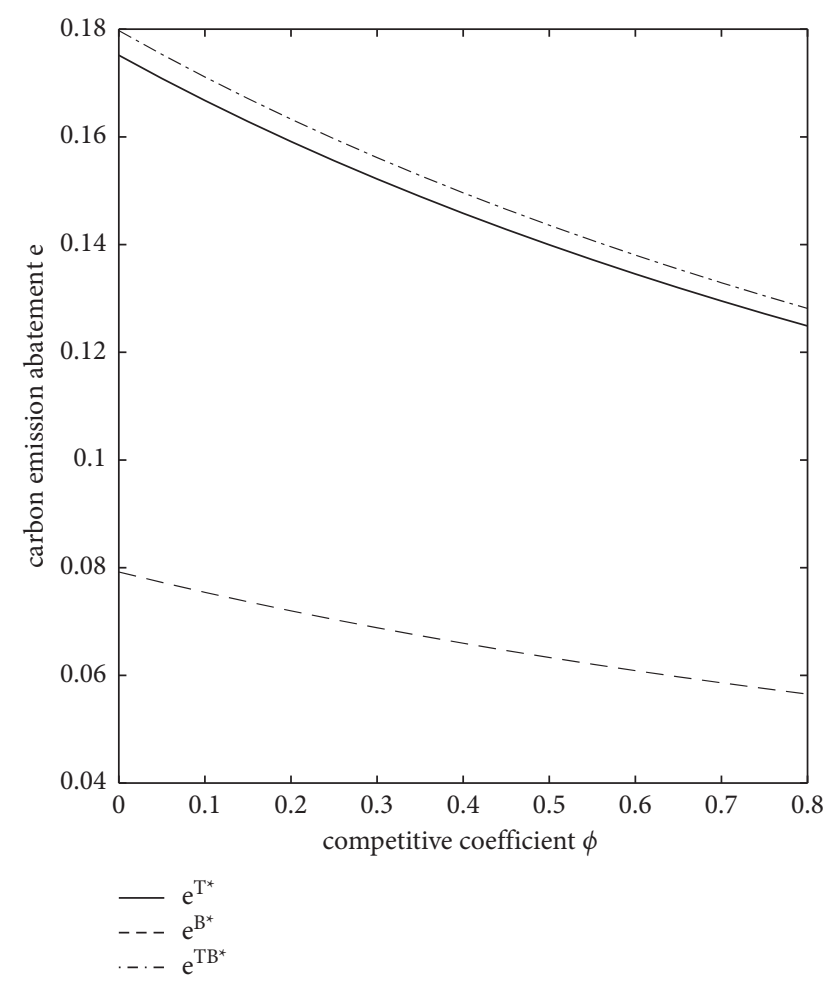

Figure 9: Impact of $\phi$ on $e$.

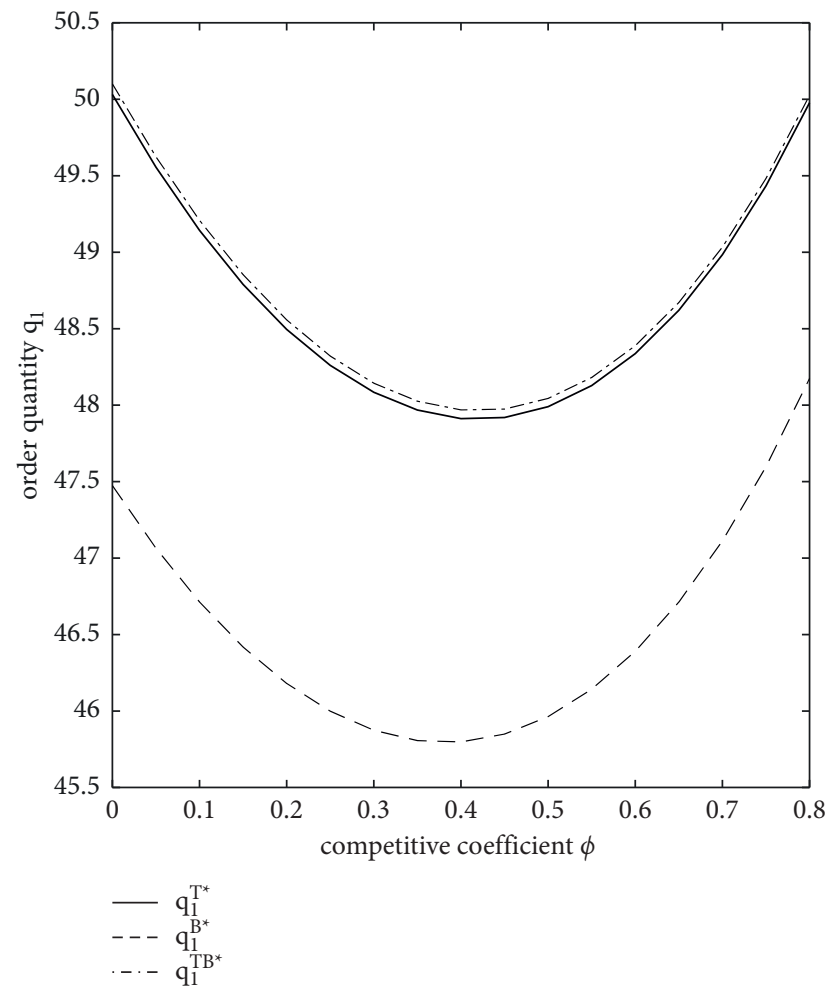

FIgURE 10: Impact of $\phi$ on $q_{1}$.

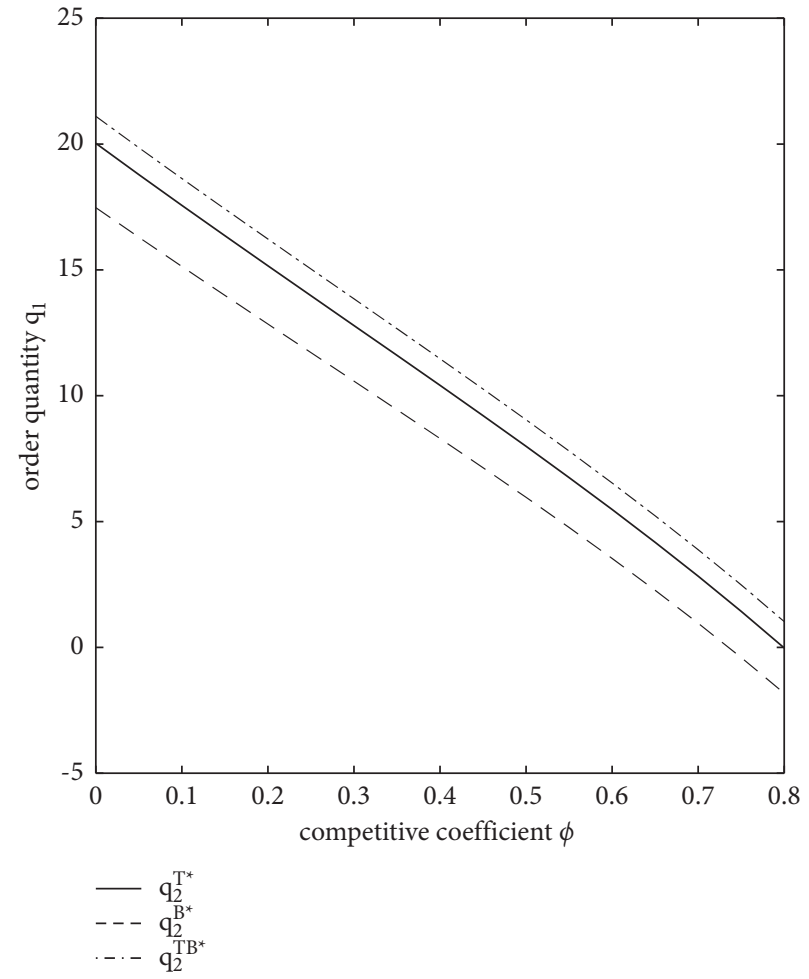

Figure 11: Impact of $\phi$ on $q_{2}$.

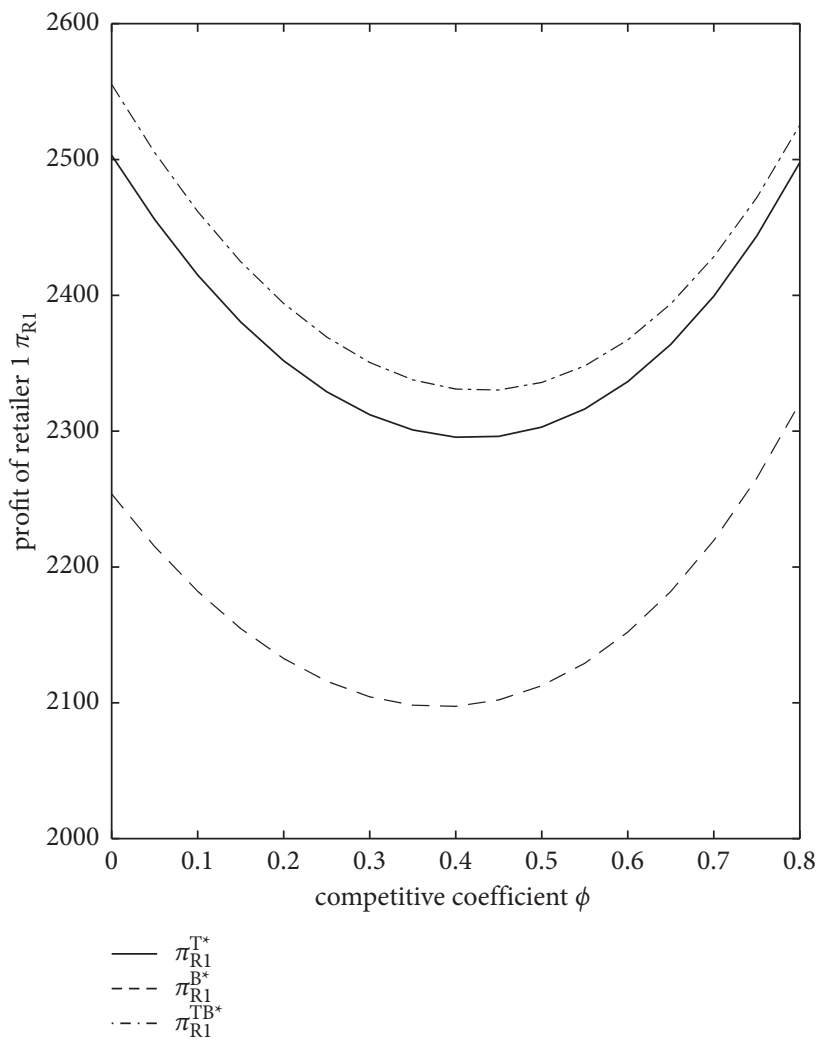

FIGURE 12: Impact of $\phi$ on $\pi_{R 1}$. 


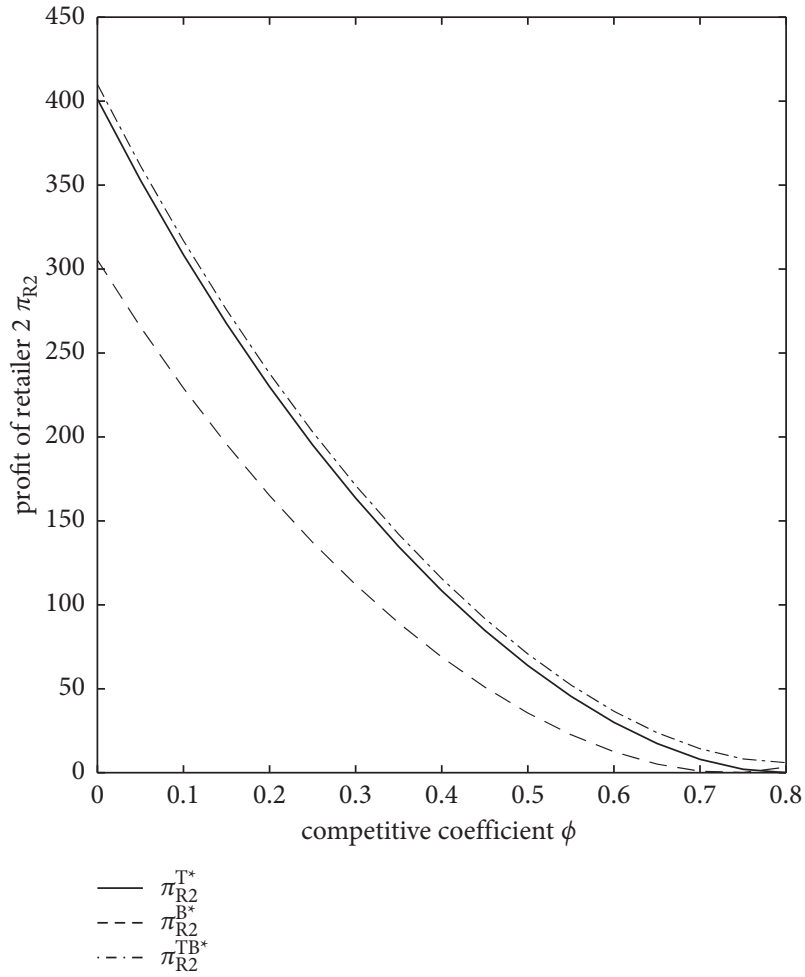

Figure 13: Impact of $\phi$ on $\pi_{R 2}$.

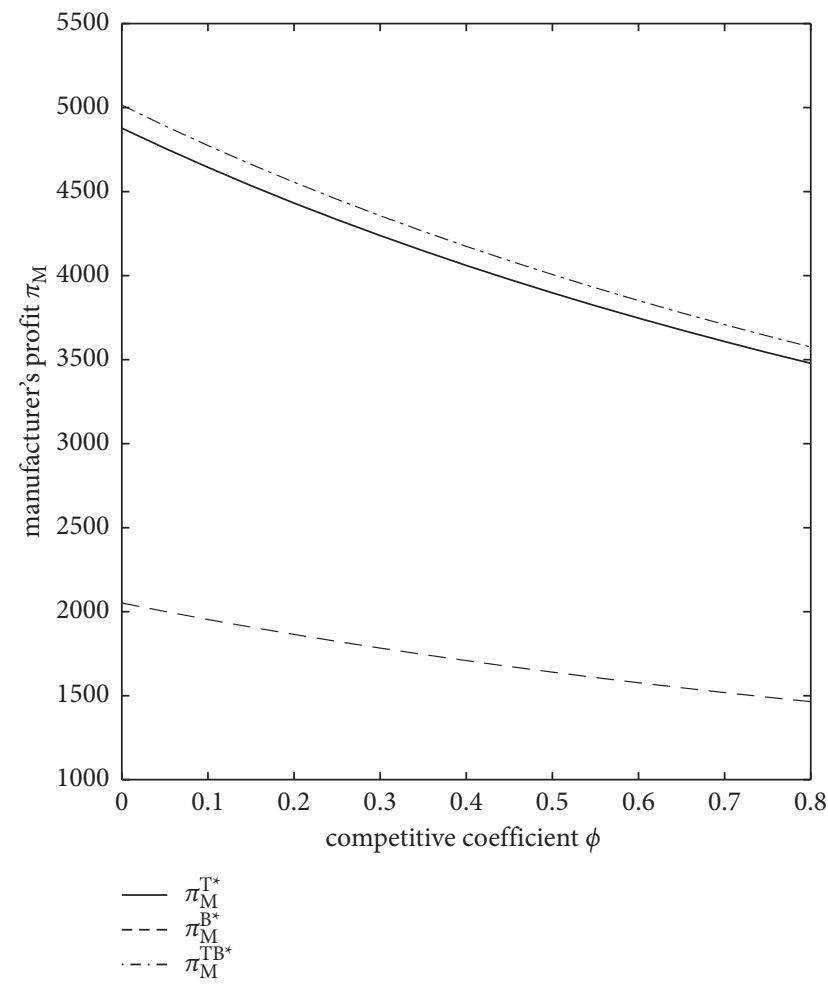

Figure 14: Impact of $\phi$ on $\pi_{M}$.

shown in Figures 13 and 14. From this set of numerical experiments, we find that market competition hurts the manufacturer and the weak retailer, and only benefits the strong retailer under certain conditions.

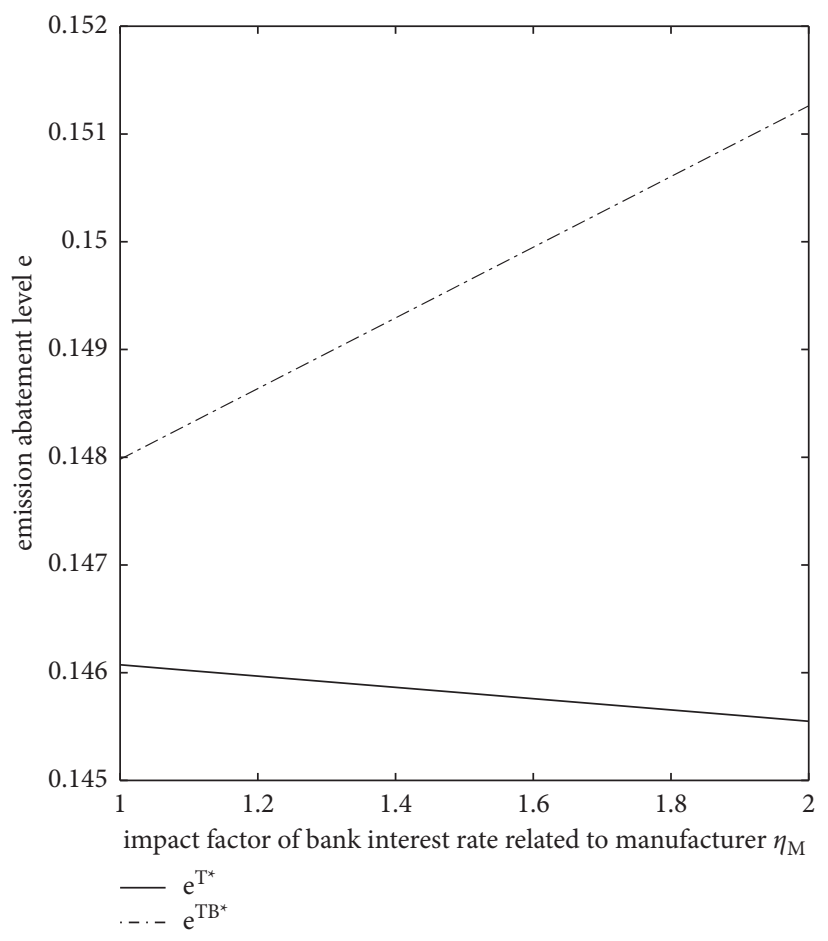

FIgURE 15: Impact of $\eta_{M}$ on $e$.

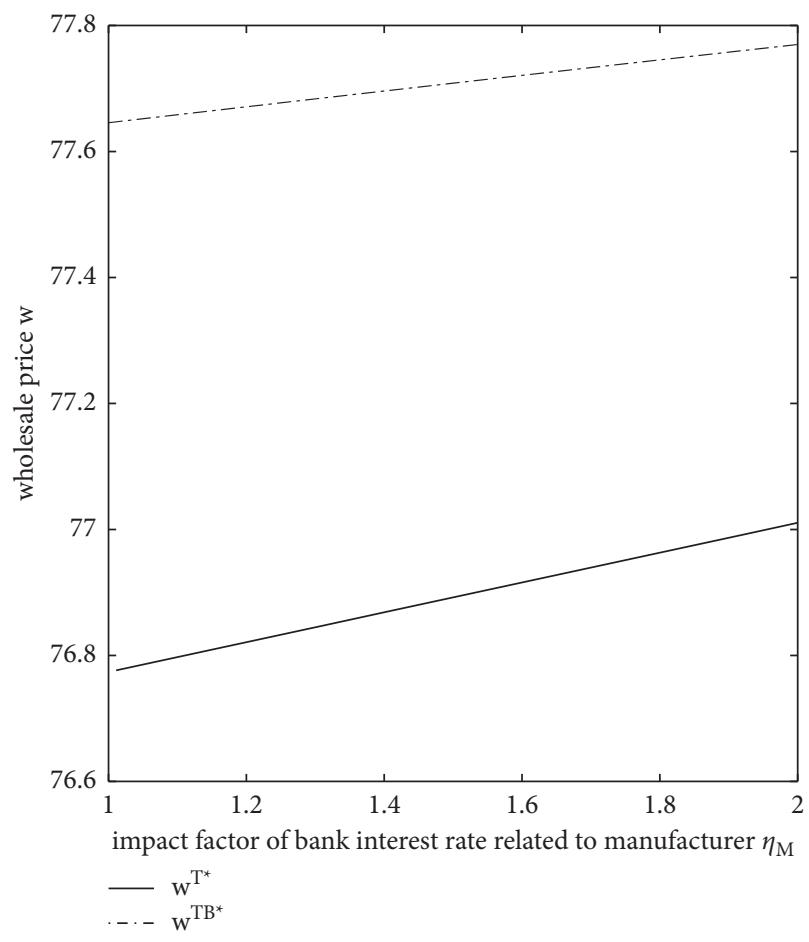

FIGURE 16: Impact of $\eta_{M}$ on $w$.

This set of numerical examples examines how the impact factor of bank interest rate related to manufacturer $\eta_{M}$ affects each member's decision and profit. As all decisions are immune to $\eta_{M}$ when the retailers adopt bank credit 


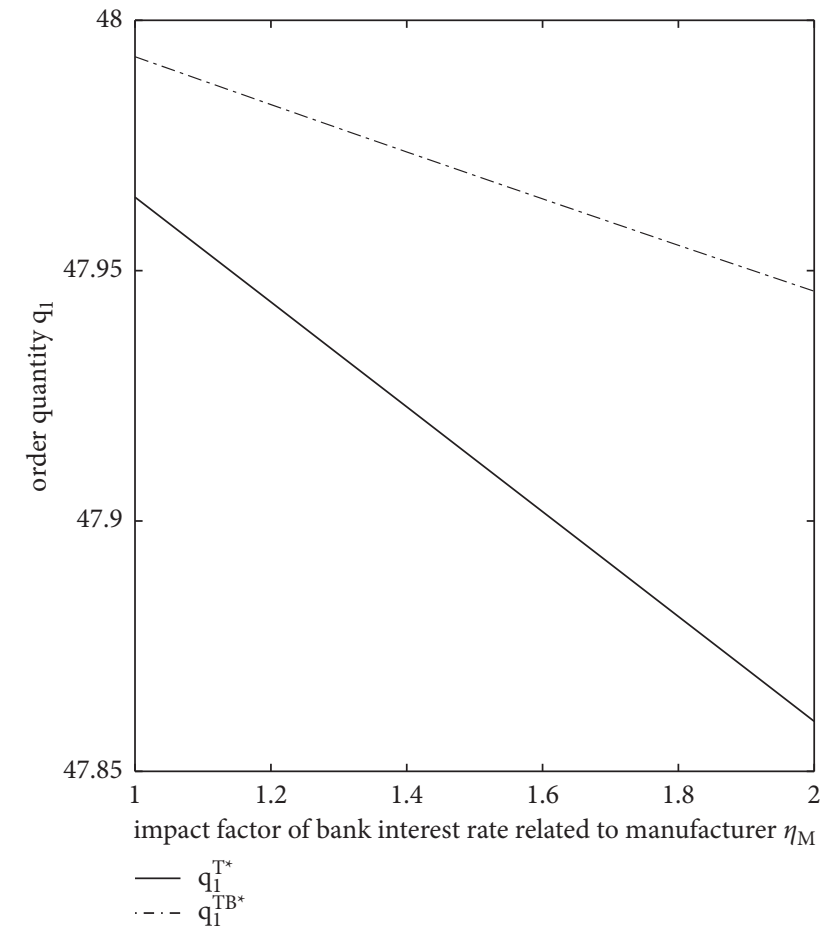

FigURE 17: Impact of $\eta_{M}$ on $q_{1}$.

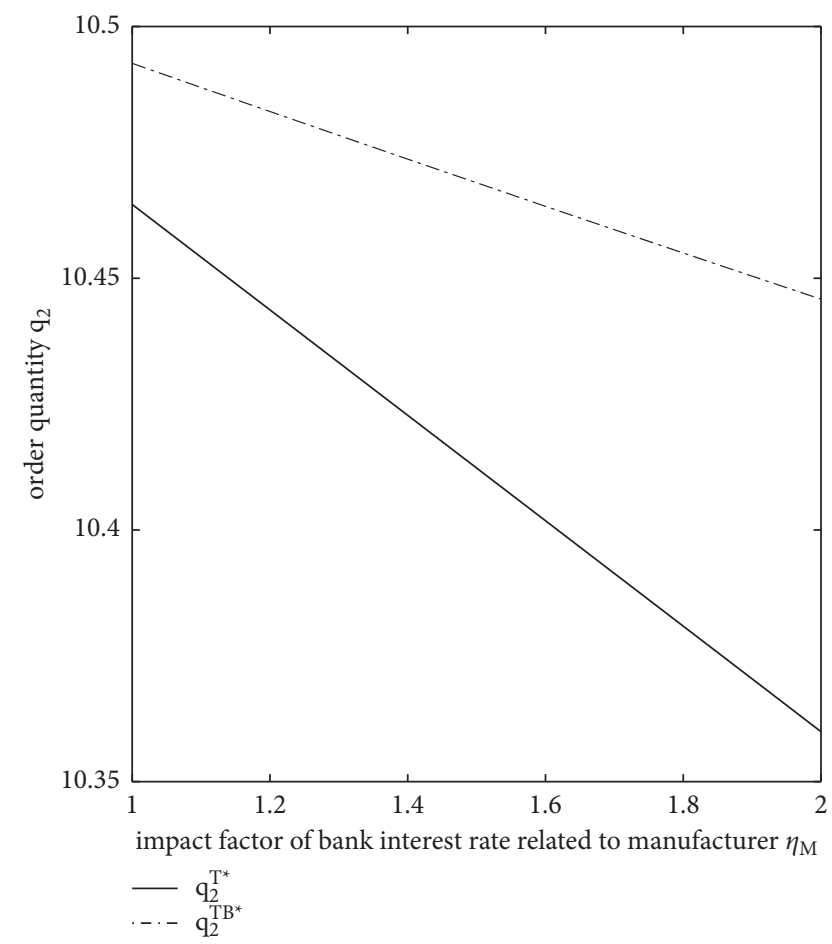

FIGURE 18: Impact of $\eta_{M}$ on $q_{2}$.

financing, we ignore the impacts of $\eta_{M}$ in bank financing scenario here. From Figure 15, we find that the emission abatement $e$ decreases in $\eta_{M}$ under trade credit financing. In this scenario, the manufacturer's all productive fund is

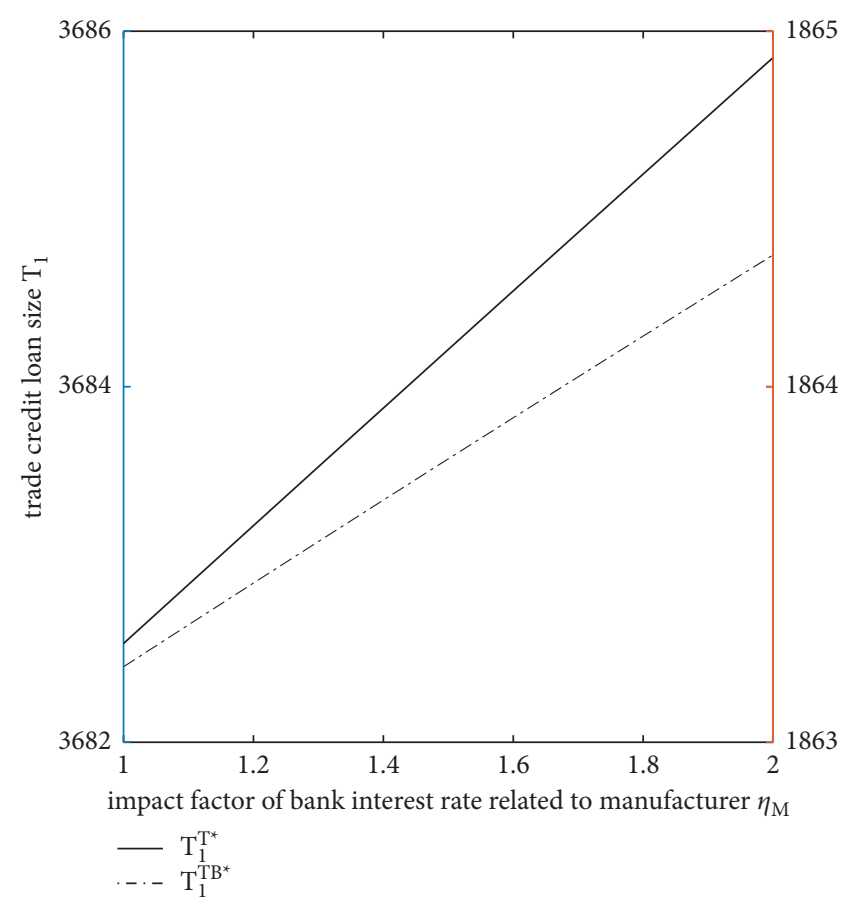

Figure 19: Impact of $\eta_{M}$ on $T_{1}$.

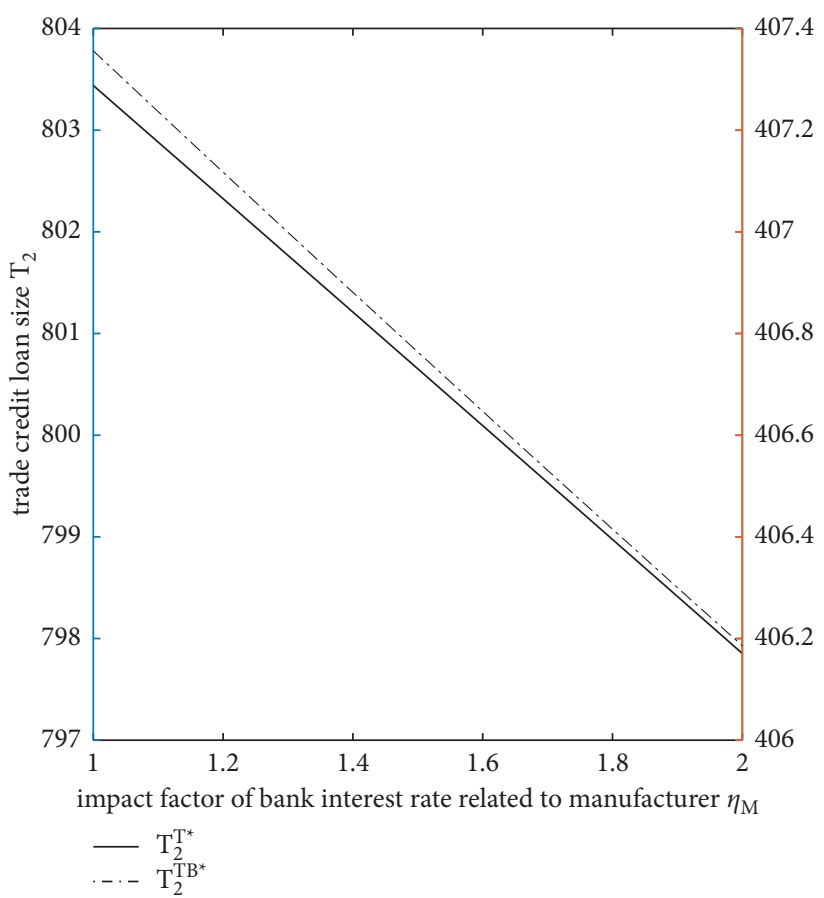

FIgURE 20: Impact of $\eta_{M}$ on $T_{2}$.

borrowed from the bank, which increases the manufacturer's financing cost. With $\eta_{M}$ increasing, the manufacturer prefers to lower the emission abatement level to save operational cost. However, when dual-channel financing is adopted, the bank financing cost is undertaken by the 


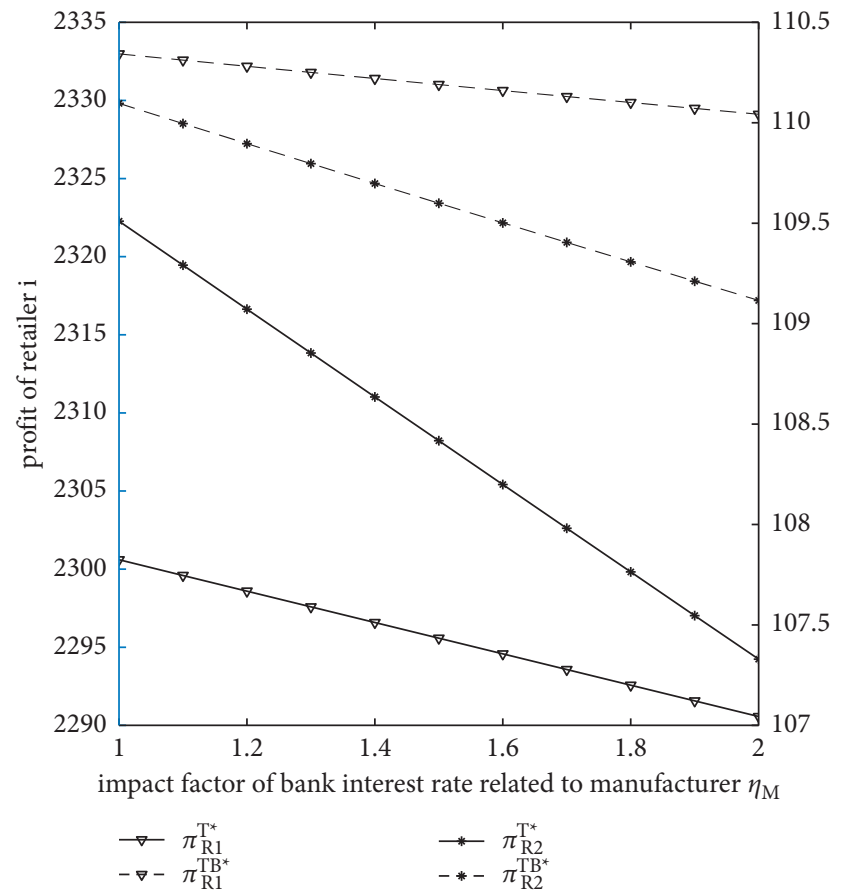

Figure 21: Impact of $\eta_{M}$ on $\pi_{R}$.

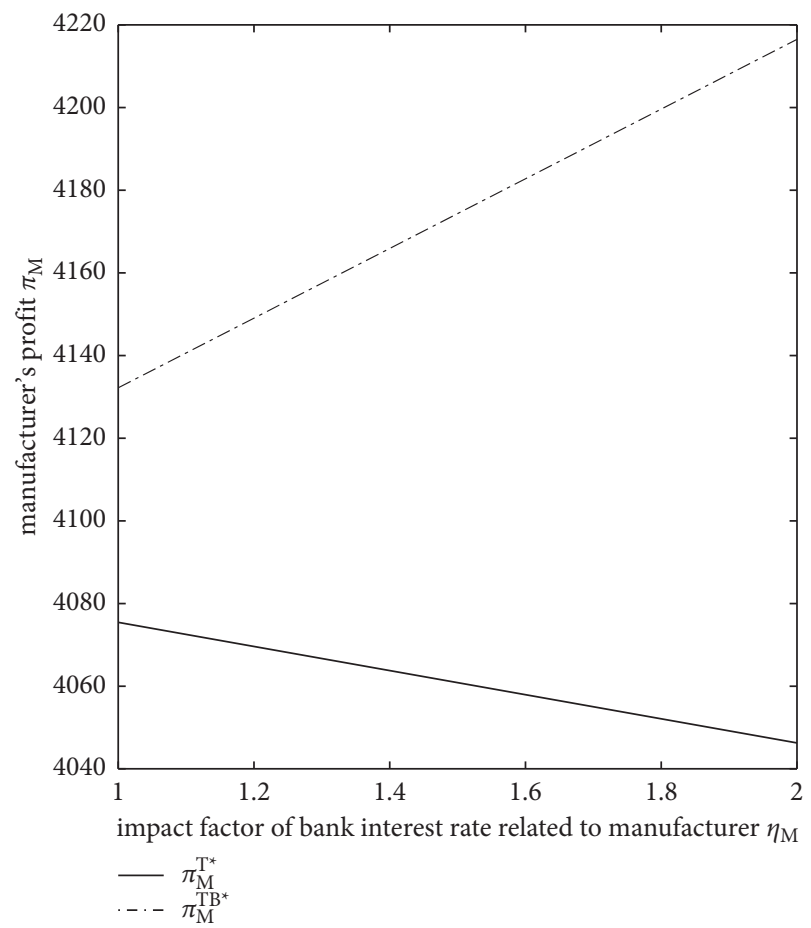

Figure 22: Impact of $\eta_{M}$ on $\pi_{M}$.

manufacturer and retailers. Then, the manufacturer can use the saved financing cost to invest in abating carbon emissions. Thus, $e$ increases in $\eta_{M}$ under dual-channel financing. For the wholesale price, the manufacturer tends to charge a higher price when financing cost increases, as shown in Figure 16.

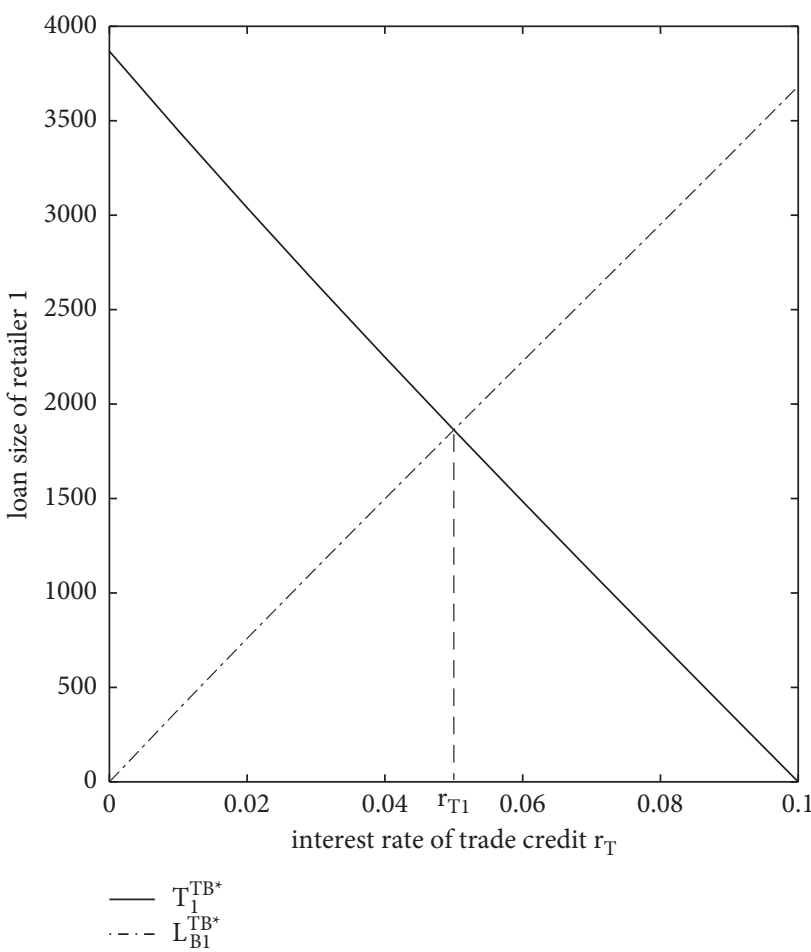

FIgURE 23: Loan size allocation of retailer 1.

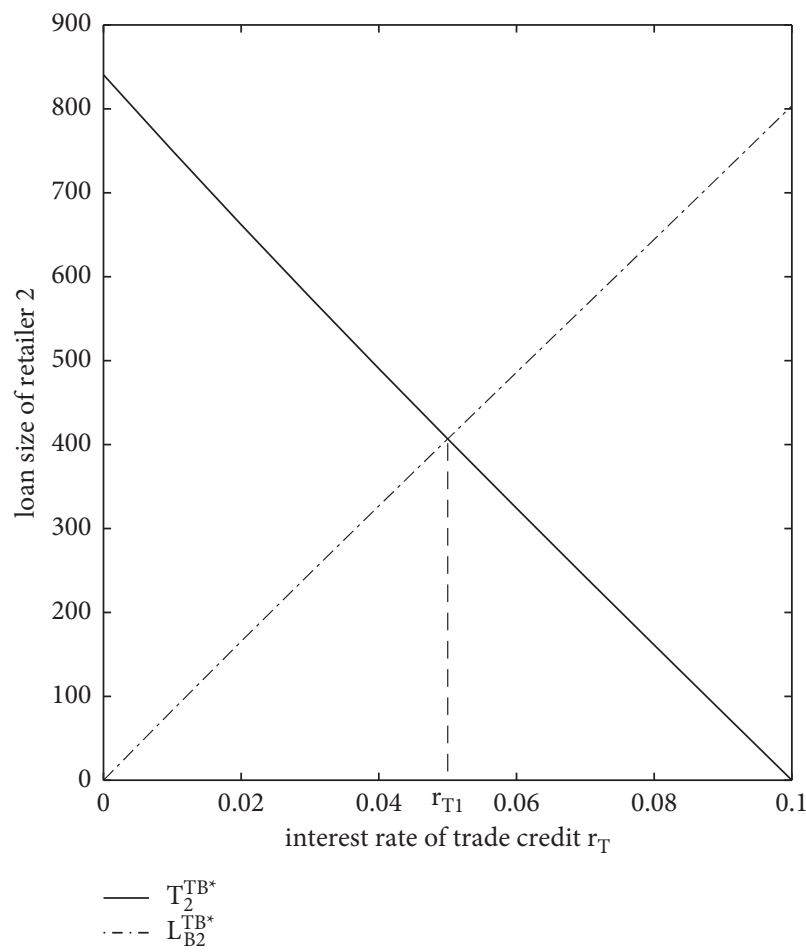

FIgURE 24: Loan size allocation of retailer 2.

We know that the manufacturer transfers some operating cost to the downstream retailers by charging a larger wholesale price. The retailers will cut the order quantities due to the inverse relationship between the wholesale price and order quantity. Thus, the retailers' order quantities 
decrease in $\eta_{M}$ regardless of using trade credit financing or dual-channel financing, which are shown in Figures 17 and 18. The two figures also show that each retailer's order quantity under dual-channel financing is larger than that under trade credit financing, which once again proves that dual-channel financing is better than trade credit financing.

With $\eta_{M}$ increasing, the increased wholesale price enhances operating cost of retailer 1 . As trade credit is better than bank credit, retailer 1 chooses to increase the loan size of trade credit instead of bank credit. Thus, $T_{1}^{T}$ and $T_{1}^{T B}$ increase in $\eta_{M}$, which are shown in Figure 19. Contrary to retailer 1, retailer 2's trade credit loan size decreases in $\eta_{M}$. According to the parameter setting, retailer 2 has a small market share. When facing a large wholesale price, retailer 2 cuts the order quantity dramatically, which is followed by a small amount of operating cost. In this scenario, there is no need for retailer 2 to borrow more money. Therefore, the trade credit loan size of retailer 2 decreases in $\eta_{M}$, which is shown in Figure 20.

On the one hand, the wholesale price increases in $\eta_{M}$; on the other hand, the order quantities decrease in $\eta_{M}$. As a result, as shown in Figure 21, the retailers' profits decrease in $\eta_{M}$. For the manufacturer, we find that the impacts of $\eta_{M}$ on her profits are different under different financing channels. When using trade credit financing, the manufacturer's profit decreases in $\eta_{M}$. This is because all the bank financing costs are borne by the manufacturer, whereas the manufacturer's profit increases in $\eta_{M}$ when using dual-channel financing. The logic behind this result is that the retailers will undertake some bank financing cost when they borrow money from the bank, which helps the manufacturer to save the operating cost. Thus, we can get the relationship between $\eta_{M}$ and $\pi_{M}$ in Figure 22.

The last set of numerical examples illustrates the retailers' loan size allocation under dual-channel financing. Figures 23 and 24 show that the loan size of trade credit decreases in trade credit interest, but the loan size of bank credit increases in $r_{T}$. It also shows that the retailers' trade credit loan size is equal to their bank credit loan size when $r_{T}=r_{T 1}$. The retailers' trade credit loan size is larger than their bank credit loan size when $r_{T}>r_{T 1}$. When $r_{T}>r_{T 1}$, the bank financing cost is less than the cost of trade credit. As rational individuals, the retailers tend to use more bank credit funds.

\section{Conclusions}

This paper analyzes a supply chain comprising one manufacturer and two retailers considering consumers' ecofriendly awareness. Different from previous work, we examine each member's optimal decision and financing strategy when different financing methods are available. Some interesting conclusion and insights are obtained in this work. The result shows that the manufacturer charges a lower wholesale price when the emission abatement cost is high. It also shows that the emission abatement level decreases the bank interest under bank credit financing, whereas it is immune to trade credit interest when only trade credit financing is adopted. When only one financing way is available, trade credit financing is better for retailers. Besides, the manufacturer also benefits from trade credit and invests in a high emission abatement level. When both financing methods are adopted, the retailers' financing strategy highly depends on the interest rates charged by the creditors. When the trade credit interest rate is twice larger than the bank interest rate, the retailers will only use bank credit. Otherwise, they borrow both from the bank and the manufacturer. Under dual-channel financing, the emission abatement is affected by the trade credit interest, and it is larger than that in the trade credit financing scenario if the bank interest rate charged on the manufacturer is relatively large.

This paper also has some limitations. For example, the demand information is common knowledge to all the members, which could be interesting to discuss the information asymmetry case in future. Besides, the retailers adopt the same financing way in this paper. More interesting results could be obtained when considering that the retailers adopt different financing channels. In addition, one supply one chain is considered in this paper; more interesting conclusions would be obtained when considering two supply chains. Another possible research direction is to investigate the case in which the decision-makers are loss-averse.

\section{Data Availability}

No data were used to support this paper.

\section{Conflicts of Interest}

The authors declare that they have no conflicts of interest.

\section{Acknowledgments}

This work was supported by the National Statistical Science Research Project (No. 2020LY089).

\section{References}

[1] M. Micheal, "A global carbon market?," Frontiers of Engineering, vol. 6, no. 1, pp. 5-18, 2019.

[2] B. Yu, J. Wang, X. Lu, and H. Yang, "Collaboration in a lowcarbon supply chain with reference emission and cost learning effects: cost sharing versus revenue sharing strategies," Journal of Cleaner Production, vol. 250, pp. 1-26, 2020.

[3] M. C. Cohen, R. Lobel, and G. Perakis, "The impact of demand uncertainty on consumer subsidies for green technology adoption," Management Science, vol. 62, no. 5, pp. 1235-1258, 2016.

[4] S. An, B. Li, D. Song, and X. Chen, "Green credit financing versus trade credit financing in a supply chain with carbon emission limits," European Journal of Operational Research, vol. 292, no. 1, pp. 125-142, 2021.

[5] N. Yan and X. He, "Optimal trade credit with deferred payment and multiple decision attributes in supply chain finance," Computers \& Industrial Engineering, vol. 147, pp. 612-627, 2020.

[6] J. Chod, "Inventory, risk shifting, and trade credit," Management Science, vol. 63, no. 10, pp. 3207-3225, 2017. 
[7] S. A. Yang, J. R. Birge, and R. P. Parker, "The supply chain effect of bankruptcy reorganization," Management Science, vol. 61, no. 10, pp. 2320-2338, 2016.

[8] D. Krass, T. Nedorezov, and A. Ovchinnikov, "Environmental taxes and the choice of green technology," Production Engineering. Research and Development, vol. 22, no. 5, pp. 10351055, 2013.

[9] D. F. Drake, P. R. Kleindorfer, and L. N. Van Wassenhove, "Technology choice and capacity portfolios under emissions regulation," Production and Operations Management, vol. 25, no. 6, pp. 1006-1025, 2016.

[10] X. Xu, P. He, H. Xu, and Q. Zhang, "Supply chain coordination with green technology under cap-and-trade regulation," International Journal of Production Economics, vol. 183, pp. 433-442, 2017.

[11] D. H. Lee, "Strategies on pricing, greenness degree, and carbon emission reduction in supply chains under single and cross distributions of green and nongreen products," Mathematical Problems in Engineering, vol. 2020, Article ID 1246536, 21 pages, 2020.

[12] B. Marchi, S. Zanoni, L. E. Zavanella, and M. Y. Jaber, "Supply chain models with greenhouse gases emissions, energy usage, imperfect process under different coordination decisions," International Journal of Production Economics, vol. 211, pp. 145-153, 2019.

[13] Z. Hong and X. Guo, "Green product supply chain contracts considering environmental responsibilities," Omega, vol. 83, pp. 155-166, 2019.

[14] S. Choi, "A loss-averse newsvendor with cap-and-trade carbon emissions regulation," Sustainability, vol. 10, no. 7 , pp. 21-26, 2018.

[15] S. Du, L. Hu, and M. Song, "Production optimization considering environmental performance and preference in the cap-and-trade system," Journal of Cleaner Production, vol. 112, pp. 1600-1607, 2016.

[16] H. Yang and W. Chen, "Retailer-driven carbon emission abatement with consumer environmental awareness and carbon tax: revenue-sharing versus Cost-sharing," Omega, vol. 78, pp. 179-191, 2018.

[17] S. Swami and J. Shah, "Channel coordination in green supply chain management," Journal of the Operational Research Society, vol. 64, no. 3, pp. 336-351, 2013.

[18] C. Dong, B. Shen, P.-S. Chow, L. Yang, and C. T. Ng, "Sustainability investment under cap-and-trade regulation," Annals of Operations Research, vol. 240, no. 2, pp. 509-531, 2016.

[19] W. Tong, D. Mu, F. Zhao, G. P. Mendis, and J. W. Sutherland, "The impact of cap-and-trade mechanism and consumers' environmental preferences on a retailer-led supply Chain," Resources, Conservation and Recycling, vol. 142, pp. 88-100, 2019.

[20] D. Ghosh and J. Shah, "Supply chain analysis under green sensitive consumer demand and cost sharing contract," International Journal of Production Economics, vol. 164, pp. 319-329, 2015.

[21] X. Shi, C. Dong, C. Zhang, and X. Zhang, "Who should invest in clean technologies in a supply chain with competition?," Journal of Cleaner Production, vol. 215, pp. 689-700, 2019.

[22] W. Zhu and Y. He, "Green product design in supply chains under competition," European Journal of Operational Research, vol. 258, no. 1, pp. 165-180, 2017.

[23] Z. Luo, X. Chen, and X. Wang, "The role of co-opetition in low carbon manufacturing," European Journal of Operational Research, vol. 253, no. 2, pp. 392-403, 2016.
[24] Y. Wang and X. Sun, "Dynamic vs. Static wholesale pricing strategies in a dual-channel green supply chain," Complexity, vol. 2019, Article ID 8497070, 14 pages, 2019.

[25] S. Tiwari, L. E. Ćardenas-Barrón, A. Shaikh, and M. Goh, "Retailer's optimal ordering policy for deteriorating items under order-size dependent trade credit and complete backlogging," Computers \& Industrial Engineering, vol. 139, pp. 545-559, 2018.

[26] F. Otrodi, R. Ghasemy Yaghin, and S. A. Torabi, "Joint pricing and lot-sizing for a perishable item under two-level trade credit with multiple demand classes," Computers \& Industrial Engineering, vol. 127, pp. 761-777, 2019.

[27] B. Marchi, J. M. Ries, S. Zanoni, and C. H. Glock, "A joint economic lot size model with financial collaboration and uncertain investment opportunity," International Journal of Production Economics, vol. 176, pp. 170-182, 2016.

[28] D. Wu, B. Zhang, and O. Baron, "A trade credit model with asymmetric competing retailers," Production and Operations Management, vol. 28, no. 1, pp. 206-231, 2019.

[29] H. Li, L. Mai, W. Zhang, and X. Tian, "Optimizing the credit term decisions in supply chain finance," Journal of Purchasing and Supply Management, vol. 25, no. 2, pp. 146-156, 2019.

[30] X. Zou and B. Tian, "Retailer's optimal ordering and payment strategy under two-level and flexible two-part trade credit policy," Computers \& Industrial Engineering, vol. 142, pp. 1-16, 2020.

[31] S. A. Yang and J. R. Birge, "Trade credit, risk sharing, and inventory financing portfolios," Management Science, vol. 64, no. 8, pp. 3667-3689, 2018.

[32] D. Ren, Y. Lan, and C. Shang, "Impacts of trade credit on pricing decisions of complementary products," Computers \& Industrial Engineering, vol. 146, pp. 515-580, 2020.

[33] N. Yan, B. Sun, H. Zhang, and C. Liu, "A partial credit guarantee contract in a capital-constrained supply chain: financing equilibrium and coordinating strategy," International Journal of Production Economics, vol. 173, pp. 122-133, 2016.

[34] J. M. Ries, C. H. Glock, and K. Schwindl, "The influence of financial conditions on optimal ordering and payment policies under progressive interest schemes," Omega, vol. 70, pp. 15-30, 2017.

[35] O. Boyabatli and L. B. Toktay, "Stochastic capacity investment and flexible vs. dedicated technology choice in imperfect capital markets," Management Science, vol. 57, no. 12, pp. 2163-2179, 2011.

[36] H. Yang, W. Zhuo, and L. Shao, "Equilibrium evolution in a two-echelon supply chain with financially constrained retailers: the impact of equity financing," International Journal of Production Economics, vol. 185, pp. 139-149, 2017.

[37] P. Kouvelis and W. Zhao, "Supply chain contract design under financial constraints and bankruptcy costs," Management Science, vol. 62, no. 8, pp. 2341-2357, 2016.

[38] J. Bing, X. Chen, and G. G. Cai, "Equilibrium financing in a distribution channel with capital constraint," Production and Operations Management, vol. 21, no. 6, pp. 1090-1101, 2012.

[39] P. Kouvelis and W. Zhao, "Who should finance the supply chain? Impact of credit ratings on supply chain decisions," Manufacturing \& Service Operations Management, vol. 20, no. 1, pp. 19-35, 2018.

[40] S. Deng, C. Gu, G. Cai, and Y. Li, "Financing multiple heterogeneous suppliers in assembly systems: buyer finance vs. bank finance," Manufacturing \& Service Operations Management, vol. 20, no. 1, pp. 53-69, 2018.

[41] C. S. Tang, S. A. Yang, and J. Wu, "Sourcing from suppliers with financial constraints and performance risk," 
Manufacturing \& Service Operations Management, vol. 20, no. 1, pp. 70-84, 2018.

[42] B. Becker and J. Josephson, "Insolvency resolution and the missing high-yield bond markets," Review of Financial Studies, vol. 29, no. 10, pp. 2814-2849, 2016.

[43] J. C. Stein, "An adverse-selection model of bank asset and liability management with implications for the transmission of monetary policy," The RAND Journal of Economics, vol. 29, no. 3, pp. 466-486, 1998.

[44] B. S. Bernanke, M. Gertler, and S. Gilchrist, "The financial accelerator in a quantitative business cycle framework," in Handbook of Macroeconomics, J. B. Taylor and M. Woodford, Eds., Elsevier, Amsterdam, Netherlands, pp. 1341-1393, 1999.

[45] J. Chod, E. Lyandres, and S. A. Yang, "Trade credit and supplier competition," Journal of Financial Economics, vol. 131, no. 2, pp. 484-505, 2019. 